\title{
Mystery of Retinal Vein Occlusion: Vasoactivity of the Vein and Possible Involvement of Endothelin-1
}

\author{
Teruyo Kida \\ Department of Ophthalmology, Osaka Medical College, Takatsuki, Japan \\ Correspondence should be addressed to Teruyo Kida; opt038@osaka-med.ac.jp
}

Received 31 May 2017; Accepted 13 July 2017; Published 20 August 2017

Academic Editor: Alfredo García-Layana

Copyright (C) 2017 Teruyo Kida. This is an open access article distributed under the Creative Commons Attribution License, which permits unrestricted use, distribution, and reproduction in any medium, provided the original work is properly cited.

Retinal vein occlusion (RVO) is a common vascular disease of retina; however, the pathomechanism leading to RVO is not yet clear. In general, increasing age, hypertension, arteriosclerosis, diabetes mellitus, dyslipidemia, cardiovascular disorder, and cerebral stroke are systemic risk factors of RVO. However, RVO often occur in the unilateral eye and sometimes develop in young subjects who have no arteriosclerosis. In addition, RVO show different variations on the degrees of severity; some RVO are resolved without any treatment and others develop vision-threatening complications such as macular edema, combined retinal artery occlusion, vitreous hemorrhage, and glaucoma. Clinical conditions leading to RVO are still open to question. In this review, we discuss how to treat RVO in practice by presenting some RVO cases. We also deliver possible pathomechanisms of RVO through our clinical experience and animal experiments.

\section{Introduction}

Retinal vein occlusion (RVO) is common vascular disease of retina. Some well-known studies in large populations indicate that RVO is the second most frequent retinal vascular disease behind only diabetic retinopathy and that RVO is the fifth leading cause of blindness [1-4]; however, the pathomechanism leading to RVO is not yet clear. In general, RVO can be classified into branch retinal vein occlusion (BRVO) and central retinal vein occlusion (CRVO), depending on the affected vein lesion. Both RVO commonly occur unilaterally and show different variations on the degrees of severity. Some RVO are resolved without any treatment and others develop the vision-threatening complications [4-6], such as macular edema, combined retinal artery occlusion [7, 8], vitreous hemorrhage [9], and glaucoma [10, 11].

Despite taking numerous clinical courses of RVO, these complications are decreasing due to the development of various therapeutic approaches in addition to early alert and treatment by internal medicine doctors for cardiovascular diseases like systemic hypertension and dyslipidemia, which are well-known risk factors of RVO [6, 12-14]. Vein congestion can lead to local hypoxia, thereby increasing vascular endothelial growth factor (VEGF) [15]. Anti-VEGF therapy is the standard treatment for RVO-related macular edema at present, and it is effective in achieving a relatively rapid resolution of macular edema in most RVO patients [16-19]. In addition, it has been reported that not only VEGF but also inflammatory cytokines are associated with RVO-related macular edema [20-22].

Interestingly, the prevalence of RVO in Japan is higher than in other countries [3, 23-27]. The Hisayama study of the general Japanese population aged 40 years or older found that the prevalence of RVO is higher in Japanese patients than in other Asians or Caucasian individuals [3]. In this situation, repeated injections are often required due to a recurrence of macular edema, and the number of injections continues to increase. Thus, it is imperative that we gain a much better understanding of the clinical condition of each patient with RVO and elucidate the undetermined mechanism of RVO.

Many questions remain regarding the clinical condition leading to RVO even though anti-VEGF therapy can save many RVO patients experiencing deteriorated vision. Why does it often occur unilaterally? Does the mechanical "obstruction" or "compression" of the venous lumen induce RVO? Does the affected vein always become thrombosed in the eye with RVO? If we assume a thrombus exists in the affected vein, why is the blood flow not completely disturbed 
in fluorescein angiography? Are systemic venous thromboembolic (VTE) diseases, such as deep venous thrombosis and pulmonary embolism, not always associated with RVO? Why is BRVO sometimes resolved by itself? Why do young patients sometimes develop RVO without dyslipidemia? Why is the photoreceptor located at the outer retina impaired by the occlusion of the retinal vein located at the inner retina in patients with RVO-related macular edema? Like antiVEGF therapy, repeated injections of anti-VEGF agent are generally admitted if patients prefer, but can the disorder of the foveal photoreceptor layer by RVO be recovered with improved visual acuity? These questions and others remain unanswered.

In this review, we discuss how to treat patients in practice by presenting some RVO cases. We also deliver possible pathomechanisms of RVO through our clinical experience and animal experiments.

\section{Clinically Basic Understanding of RVO}

2.1. Epidemiology of RVO. Retinal vein occlusion (RVO) is the second most frequent retinal vascular disease behind only diabetic retinopathy, and it is the fifth leading cause of blindness [1-4]. Generally, RVO is classified into BRVO and CRVO depending on the affected vein lesion. BRVO was first reported in 1896 [28]. It commonly occurs unilaterally at the arteriovenous crossing. In most cases of BRVO, the artery is located anterior to the vein at the affected arteriovenous crossing $[29,30]$. In some cases, the vein is anterior to the artery at the crossing. CRVO is caused by a circulatory disturbance at the trunk of the central retinal vein near the lamina cribrosa. CRVO seems to have been first reported by Coats in 1904, who suggested dividing the clinical conditions of CRVO into two types: those with deteriorated vision and poor prognoses and those with much better vision and prognoses [31].

The prevalence of RVO has been reported by Rogers et al. [32]. They suggested that approximately 16 million people may have the condition, and the age- and sex-standardized prevalence was 5.2 per 1000 for any RVO, 4.42 per 1000 for BRVO, and 0.80 per 1000 for CRVO. There was no difference between the age-standardized prevalence rates in men and women, but the prevalence increases with age $[1,32]$. It is known that the major risk factors for RVO include increasing age, systemic hypertension, dyslipidemia, coexisting cardiovascular diseases, and diabetes mellitus [2, 6, 3337]. Therefore, affected patients are also at higher risk for future cardiovascular events. Interestingly, the risk factor of systemic hypertension is higher in BRVO than in CRVO. In addition, RVO is related to glaucoma [2, 36, 38-40].

2.2. Clinical Common Points and Differences between BRVO and CRVO. Both BRVO and CRVO have the following common points: patients with RVO often have systemic hypertension and/or dyslipidemia as a preexisting disease; they show some findings of superficial or deep retinal hemorrhages, cotton wool spots (CWS), venous dilatation, and venous tortuosity in their ocular fundus; they are divided into ischemic and nonischemic [41, 42]; prolonged cases of macular edema lead to poor prognoses. However, while BRVO and CRVO share the commonalities listed above, CRVO is not simply a severe case of BRVO.

There are also significant differences between BRVO and CRVO. CRVO develop neovascular glaucoma, which lead to the risk of blindness [43]. In cases of severe venous obstruction, arterial perfusion is delayed and can be accompanied by artery occlusion [44]. CRVO cases are induced more by variables other than systemic hypertension and arteriosclerosis, unlike BRVO [45]. In addition, natural history is different between BRVO and CRVO. The Branch Vein Occlusion Study showed that visual acuity improved in $40 \%$ of eyes with BRVO after 3 years, 34\% with visual acuity beyond 20/40 without any treatment [46]. Hayreh and Zimmerman [28] stated that, overall, visual acuity improved or remained stable in about $80 \%$ of eyes with BRVO. Rogers et al. [4] reported the natural history of BRVO that visual acuity is generally improved without intervention, although clinically significant improvement beyond 20/40 was uncommon. CRVO differs significantly from BRVO when it comes to its natural history. The Central Vein Occlusion Study found that patients who had poor visual acuity at the first visit $(<20 / 200)$ had an $80 \%$ chance of having a visual acuity less than $20 / 200$ at their final visit, whether perfused or nonperfused initially [41]. In addition, $15 \%$ of CRVO eyes with perfusion converted to ischemia in the first 4 months of follow-up, which jumped to $34 \%$ after 3 years [41, 47]. Final visual acuity, upon resolution of macular edema, was $20 / 100$ or better in only $12 \%$ with ischemic CRVO eyes [48]. McIntosh et al. [49] argued that untreated eyes with CRVO generally have poor visual acuity, which declined further over time. One-quarter of eyes with nonischemic CRVO convert to ischemic CRVO. Thus, early intervention is needed in CRVO, not only ischemic but also nonischemic, to improve vision prognosis.

\section{Treatments for RVO in Practice}

Recently, various therapeutic approaches have been developed, such as anti-VEGF therapy and the intravitreal implant of steroids [50]. For RVO-related macular edema, intravitreal injection of anti-VEGF agent, sub-Tenon's injection of triamcinolone acetonide, grid laser photocoagulation, and vitrectomy are available. For RVO with neovascularization, retinal photocoagulation is effective. In young patients with CRVO, there is a possible involvement of inflammation, and prednisolone is sometimes administered internally [51, 52]. Overall, anti-VEGF therapy seems to be the standard treatment for RVO-related macular edema in recent literatures. Visual acuity is improved in most cases, and there are few complications. It is known that the RVO-related macular edema responds well to intravitreal anti-VEGF because the predominant cause of macular edema is the high levels of VEGF $[16,53]$. However, some RVO cases such as having microaneurysms and chronic inflammation do not respond to anti-VEGF agents and repeated injections are needed in chronic state. The high cost of VEGF inhibitors is a significant problem [54]. Thus, it would be efficacious to treat macular edema by other techniques or drugs. To do that, it is necessary to discover the pathomechanisms of RVO. 

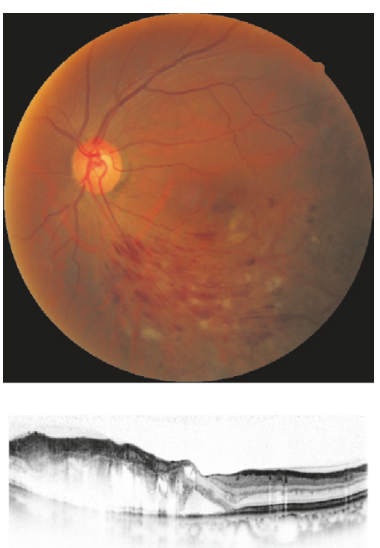

(a)
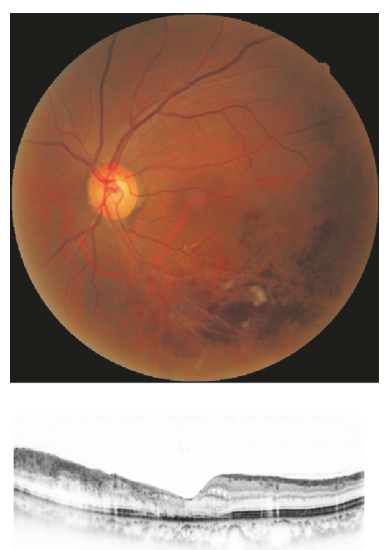

(b)
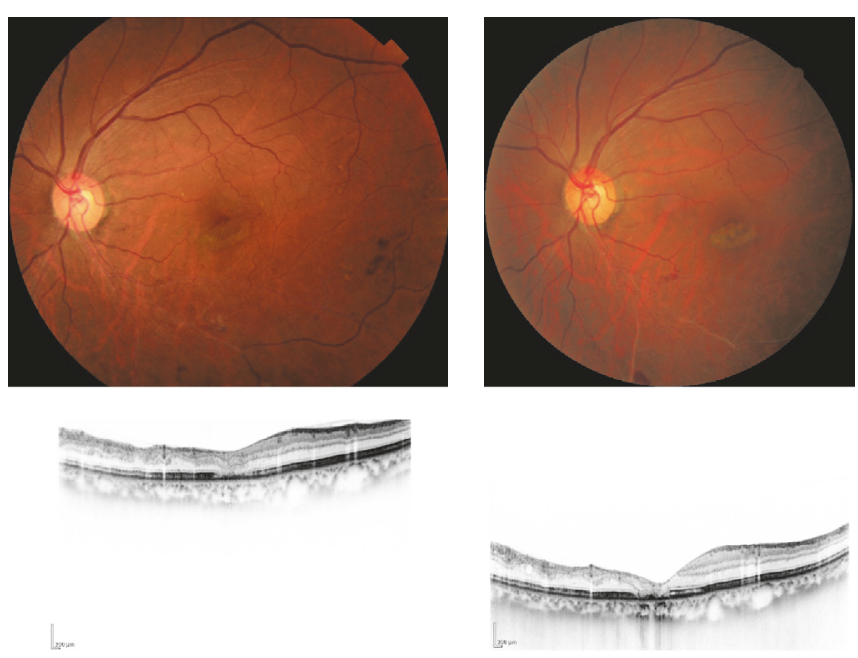

(d)

Figure 1: A case of 61-year-old female, BRVO with macular edema. (a) Pretreatment (February, 2014) and (b) one month, (c) six months, and (d) 3 years after intravitreal injection of ranibizumab. Macular edema was decreased and the visual acuity was dramatically improved from 20/50 to 20/20 3 years after the treatment. There has been no recurrence to date.
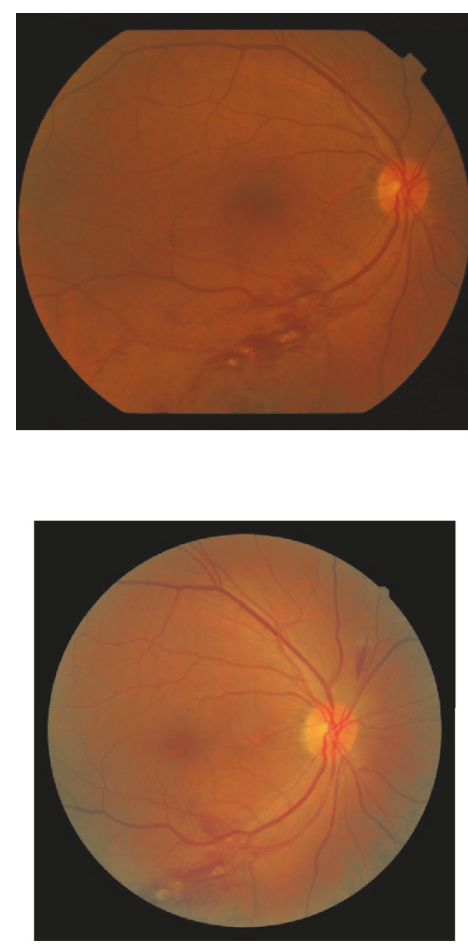
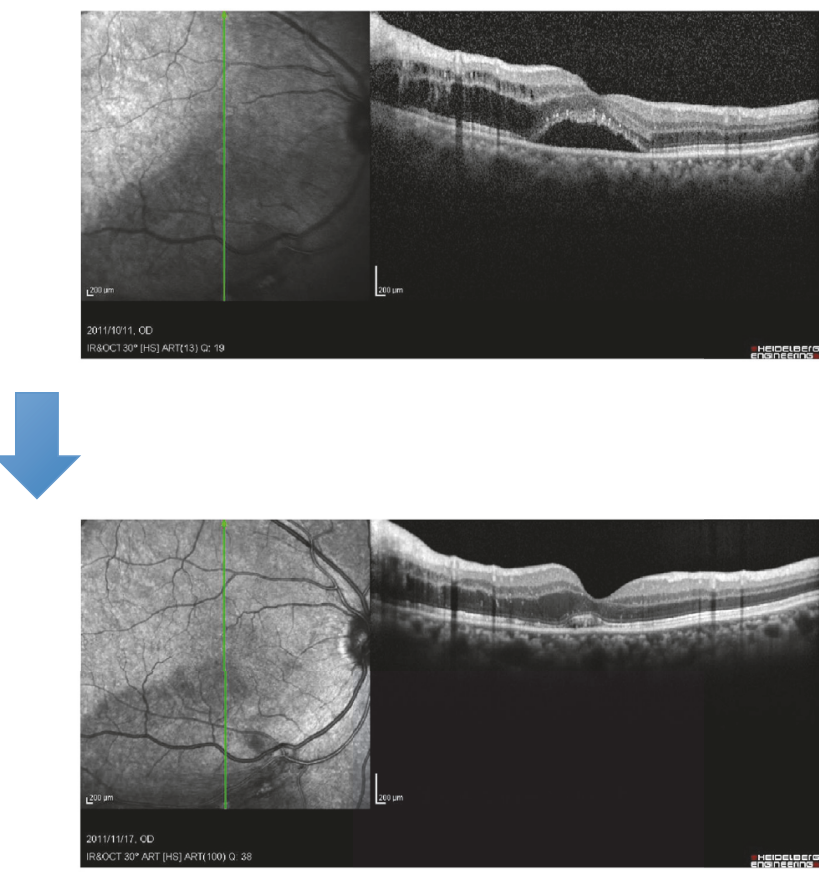

FIgURE 2: A case of 71-year-old man, BRVO with macular edema before and after treatment of systemic hypertension. His blood pressure was $165 / 87 \mathrm{mmHg}$ at the first visit. Macular edema was resolved with greatly improved VA from 20/50 to 20/20 1 month after treatment of angiotensin receptor blocker. Anti-VEGF agent was not needed.

In this article, some clinical cases that we experienced are introduced and information on treatment is found in Figures $1-5$. In short, at the first visit, we clerk every patient with $\mathrm{RVO}$ and measure his or her blood pressure. If the patient's blood pressure is high, we recommend they see an internal doctor to recheck the blood pressure and to run labs including cholesterol, triglycerides, and blood glucose, among others. If the patient's RVO develops macular edema with decreased vision, we consider our earlier intervention of anti-VEGF therapy at the initial visit, especially for some patients who drive a car daily, to improve their visual acuity to be able to drive safely. As a macular finding, foveal subretinal 


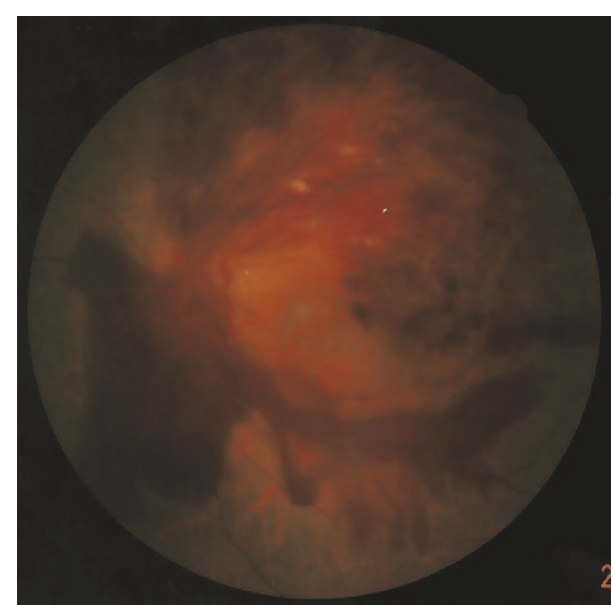

(a)

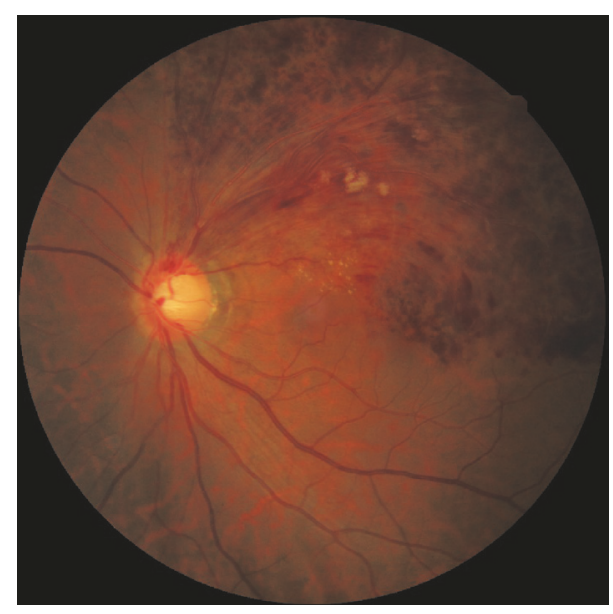

(c)

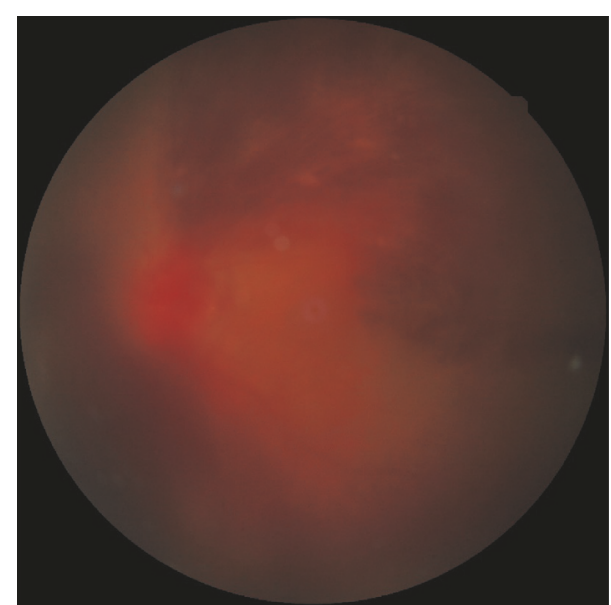

(b)

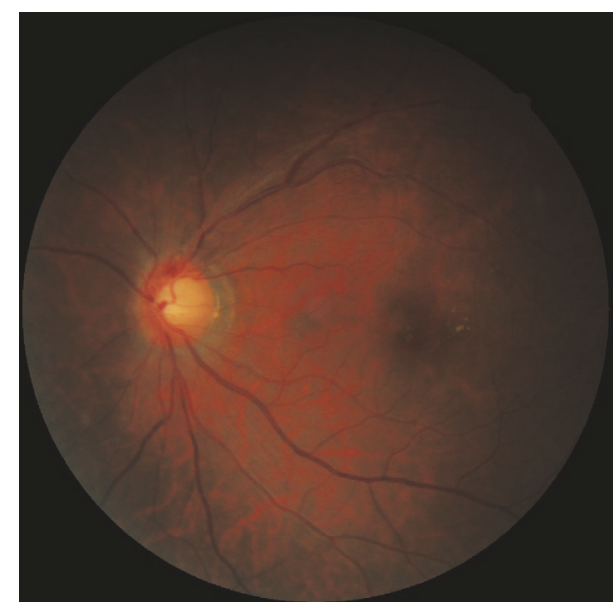

(d)

FIGURE 3: A case of 47-year-old man, preretinal hemorrhage and vitreous hemorrhage (VH) with BRVO. His fundus photos (a) at primary care doctor's clinic (February 1, 2012) and (b) the next day at the first visit. Vitrectomy for VH was planned, but VH was disappeared after one week (c). Laser photocoagulation for large nonperfusion area with neovascularization was conducted. His visual acuity was improved to $20 / 20$ and maintained without recurrence to date (d).

hemorrhage is not uncommon in RVO and may cause subsequent damage to the foveal photoreceptor layer $[55,56]$. To avoid the poor visual function, early treatment should be started for foveal subretinal hemorrhage. Subretinal hemorrhage encompasses the atrophy of retinal pigment epithelium (RPE) and fibrosis. Anti-VEGF therapy is also effective for foveal subretinal hemorrhage in RVO.

\section{RVO and Ocular Circulation}

In patients with RVO, retinal circulation is delayed. It is also important to evaluate the degree and area of blood flow disturbance by using fluorescein angiography (FA) and/or optical coherence tomography (OCT) angiography.

There were many efforts made by researchers and ophthalmologists to evaluate the changes in fundus circulation using FA, indocyanine green angiography (IA), laser Doppler velocimetry, laser speckle flowgraphy, and the Oxymap ${ }^{\text {TM }}$ in RVO for years before the developed OCT angiography [57-78]. It is important to consider the perfusion status in each patient with RVO. However, it remains unclear why suppression of VEGF in the vitreous by anti-VEGF agents is so effective for macular edema. Thus, we need to detect the changes in chorioretinal circulation and optic nerve head blood flow before and after treatment. To do this, we provide some cases measured by laser speckle flowgraphy before and one month after intravitreal injection of an anti-VEGF drug.

Optic nerve head ocular blood flow did not significantly change before and after the injection of the anti-VEGF agent, but chorioretinal circulation was decreased transiently in most treatment-effective cases of macular edema with RVO (Figures 6 and 7). It is well-known that VEGF upregulates endothelial nitric oxide synthase (eNOS), which in turn synthesizes nitric oxide (NO) $[79,80]$. As a result, the blood flow is increased by vasodilation through $\mathrm{NO}$, a vasodilator from vascular endothelium. In our clinical experience, the rate of decrease in chorioretinal tissue circulation following the use of an anti-VEGF drug seems to be case dependent. Interestingly, chorioretinal blood flow did not decrease after 


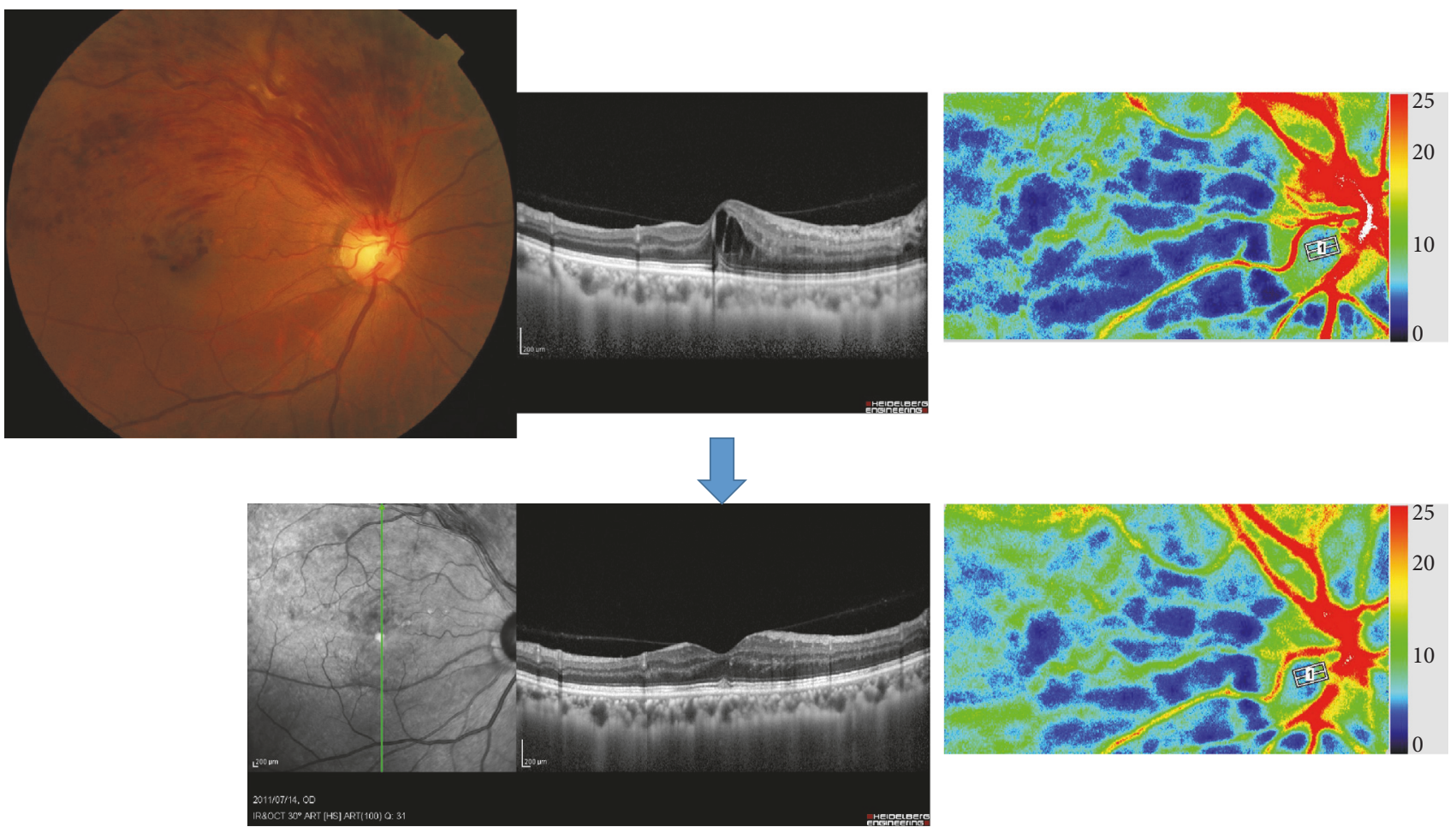

FIGURE 4: A case of 50-year-old female, BRVO with macular edema. Upper: her visual acuity was 20/25 with macular edema at the first visit. Lower: laser photocoagulation for large nonperfusion area was performed. Her macular edema was resolved with her improved visual acuity of 20/20. We also measured chorioretinal blood flow by laser speckle flowgraphy. Chorioretinal blood flow was not decreased different from a case of anti-VEGF therapy.

treatment in naïve cases of macular edema, which are rarely seen in RVO (Figure 8).

During our clinical researches for ocular blood flow in patients with $\mathrm{RVO}[37,81]$, we encountered a transient increase in retinal cotton wool spots (CWS) following antiVEGF therapy for the treatment of macular edema secondary to CRVO (Figures 9 and 10). We reported a variety of ocular fundus photos in patients with CRVO [82]. CWS are accumulations of cytoid bodies formed through overproliferation and degeneration of axoplasmic organelles, and they are recognized as signs of acute ischemia within the nerve fiber layer $[57,83]$. If too much suppression of VEGF by an antiVEGF agent occurs in a patient with RVO-related macular edema, it might induce too much decrease of chorioretinal blood flow, and there are some reports of ischemic change after anti-VEGF therapy [84-90]. VEGF is known to stimulate the production of $\mathrm{NO}$, which is an endothelium-derived relaxing factor, and then increases the blood flow. Anti-VEGF agents such as bevacizumab have a vasoconstrictor effect [87], and the animal experiment showed that bevacizumab immune complexes activate platelets and induce thrombosis in mice [91, 92]. We found a transient increase of CWS after anti-VEGF therapy in patients with CRVO, but macular edema, retinal hemorrhage, and visual acuity were improved in almost every case [82].

Recently, the technology of OCT imaging has progressed rapidly, and OCT angiography is a popular tool for evaluating the pathology of RVO. Some papers found out that
OCT angiography can visualize microvascular abnormalities equally well or better than FA $[93,94]$, and the deep capillary plexus appears to be more severely affected than the superficial capillary plexus in RVO [95]. This finding might lead to the discovery of the pathological condition of abnormal blood flow in RVO.

\section{Possible Pathomechanism of RVO}

The pathomechanism leading to RVO is not yet clear. BRVO commonly occurs at the arteriovenous crossing. It is assumed that the diseased artery mechanically compresses the vein. However, it has been reported that the retinal vein seems to run deep under the artery at the crossing in eyes with arterial overcrossing, and the venous lumen often appears to be preserved, even at the arteriovenous crossing, as observed by thin sectioning with optical coherence tomography (OCT) in patients with acute BRVO $[30,96]$. In addition, it is possible that the vein locally constricts actively due to an altered biochemical environment.

The tortuosity of the vein is one clinical finding in CRVO. Muraoka et al. [97] reported that OCT can be used to visualize anteroposterior venous tortuosity and associated structural changes to the retinal parenchyma. This indicates that the vein itself has vasoactivity, and this phenomenon is associated with the pathomechanism of CRVO. Reviewing papers regarding RVO and vasoactivity, a brief report by Catier et al. 14 years ago found that a patient with vasospasms 


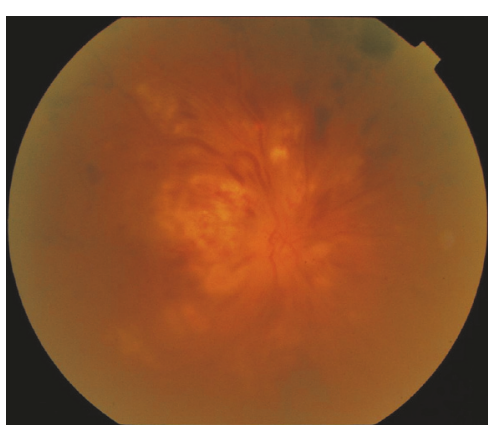

(a)

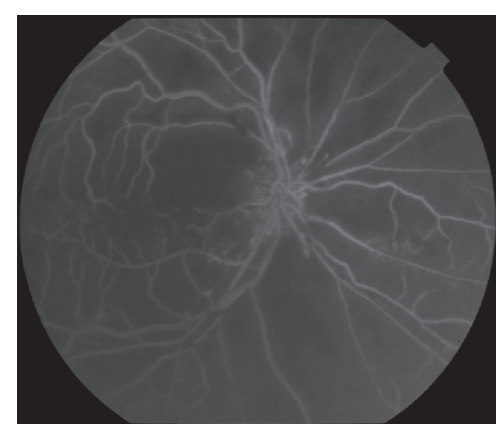

(b)

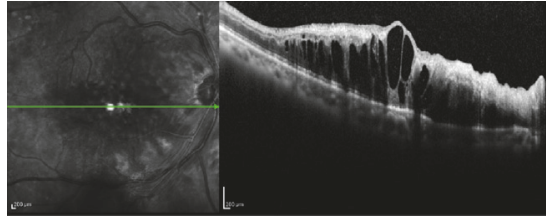

(c)

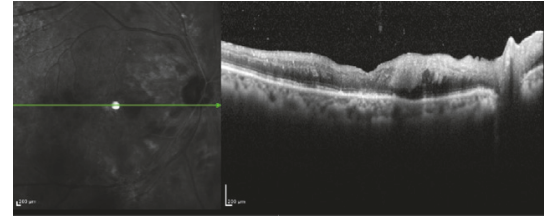

(d)

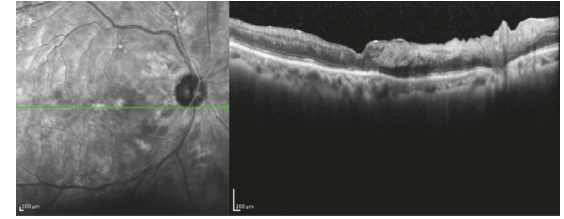

(e)

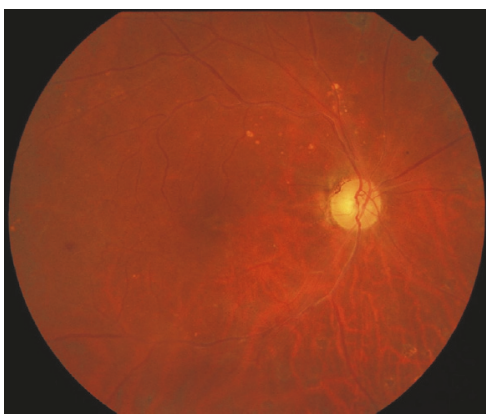

(f)

FIgURE 5: A case of 76-year-old man, ischemic CRVO with cataract. (a) His fundus photo and (b) FA at the first visit. His visual acuity was hand motion. Cataract surgery was performed and then his eye was treated with intravitreal injection of ranibizumab. OCT imaging at (c) pretreatment and (d) one week and (e) one month after anti-VEGF therapy. (f) Fundus photo one year after the treatment. His visual acuity was $20 / 1000$.

during impending CRVO was found by taking indocyanine green videoangiography [63]. In addition, Paques et al. [98] found venous nicking without arteriovenous contact by adaptive optics imaging in 2015. Recently, Yu et al. [99] suggested local modulation of retinal vein tone by using isolated perfused porcine retinal vein. CRVO is found at the trunk of the central retinal vein near the lamina cribrosa. Kang et al. [100] documented the morphometric features of arterial and venous endothelia in the different laminar regions of normal human optic nerve heads. They found an arterial-like appearance of venous endothelium in the posterior lamina cribrosa, where pressure gradient forces are predicted to be greatest and the luminal diameter of the central retinal vein is known to be narrowest, which implicates this as a site of altered hemodynamic stress. These findings by above authors are potential ways to visualize vasoactivity of the vein, and it is important to find out the pathomechanism of CRVO.

In addition, these interesting new findings may be able to act, leading to CRVO and normal tension glaucoma (NTG). The pathomechanism of NTG is also unknown. Because of this, we retrospectively investigated 234 Japanese CRVO patients over 5 years, with follow-ups of more than 12 months, and evaluated the prevalence of glaucoma [101]. Of the 234 CRVO patients, 18 (7.7\%) were diagnosed with 10 NTG or 8 primary open-angle glaucoma cases (POAG). The proportion of NTG with systemic hypertension was low. Interestingly, intraocular pressure (IOP) of NTG patients was significantly elevated at the initial CRVO evaluation, even in the presence of antiglaucoma drugs. It is already known that increased retinal venous pressure occurs in RVO [102], and, among the patients with POAG, spontaneous venous pulsation was less common in patients with low IOP at all stages of disease [103].

Going back now to RVO and VEGF, the congestion of the vein in RVO can lead to local hypoxia, thereby increasing VEGF, which in turn contributes to macular edema [104, 105]. Anti-VEGF therapy leads to the rapid reduction of macular edema and an improvement in visual function [106]. However, anti-VEGF therapy does not improve visual acuity in every patient with RVO, although a regression in macular edema is present after performing the therapy (Figure 11). 

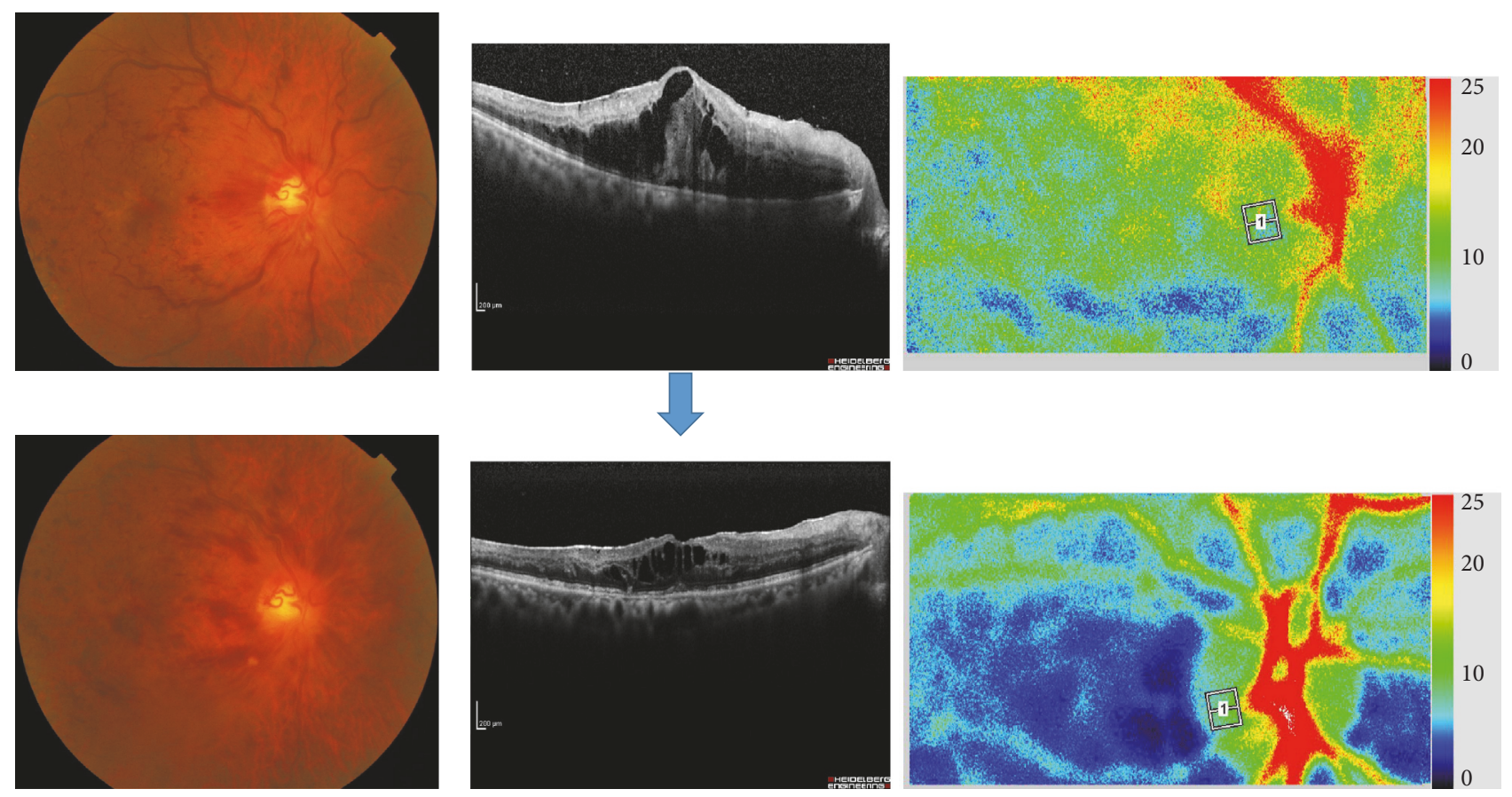

FIGURE 6: A case of 71-year-old man, CRVO with macular edema. Upper: pretreatment (August, 2011); lower: one month after intravitreal injection of bevacizumab (IVB). Macular edema was decreased and his visual acuity was changed from 20/200 to 20/100. We also measured optic nerve head and chorioretinal blood flow by laser speckle flowgraphy. Blood flow in optic nerve head was not significantly changed; however, chorioretinal blood flow was decreased one month after anti-VEGF therapy.
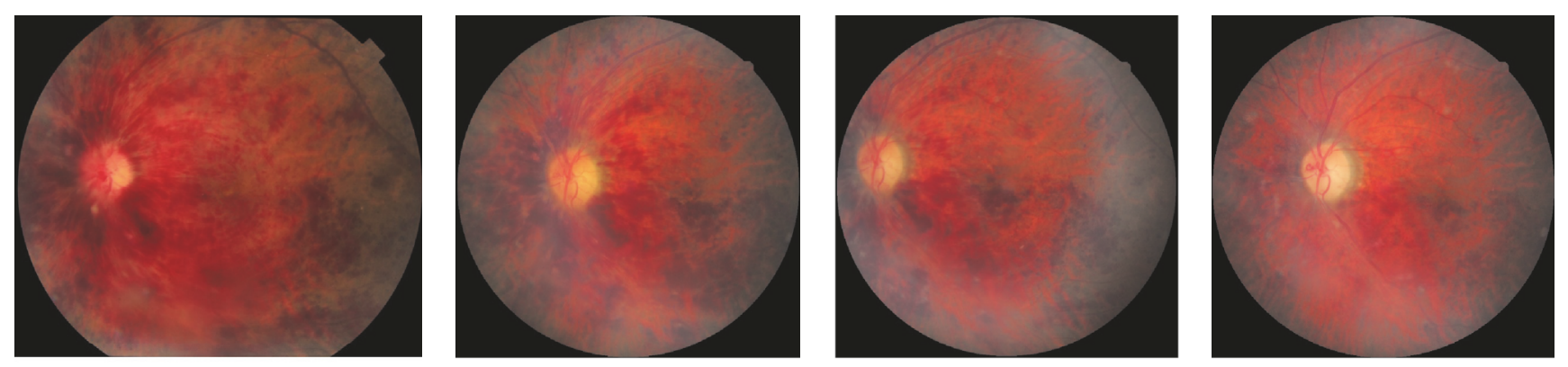

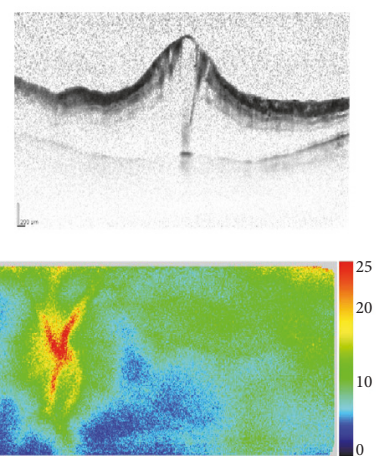

(a)
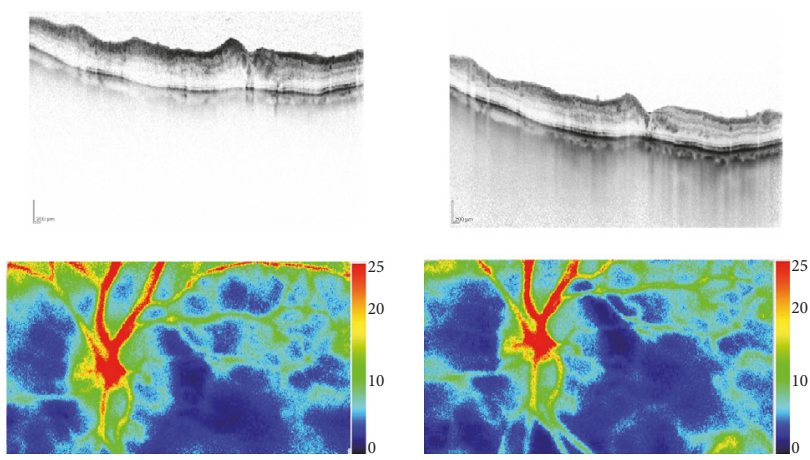

(c)

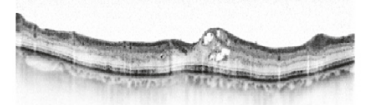

Lroum

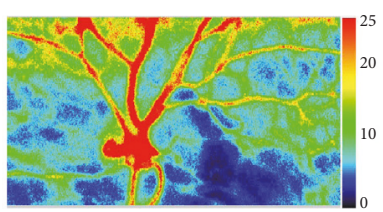

(d)

FIGURE 7: A case of 84-year-old female with CRVO. Her ocular fundus with macular OCTs and imaging of laser speckle flowgraphy at the initial visit (a) and two weeks (b), one month (c), and 3 months after intravitreal injection of ranibizumab (d). Her visual acuity was 20/400, 20/200,20/200, and 20/100, respectively. Chorioretinal blood flow was decreased two weeks and one month after anti-VEGF therapy and then increased 3 months after the injection. 

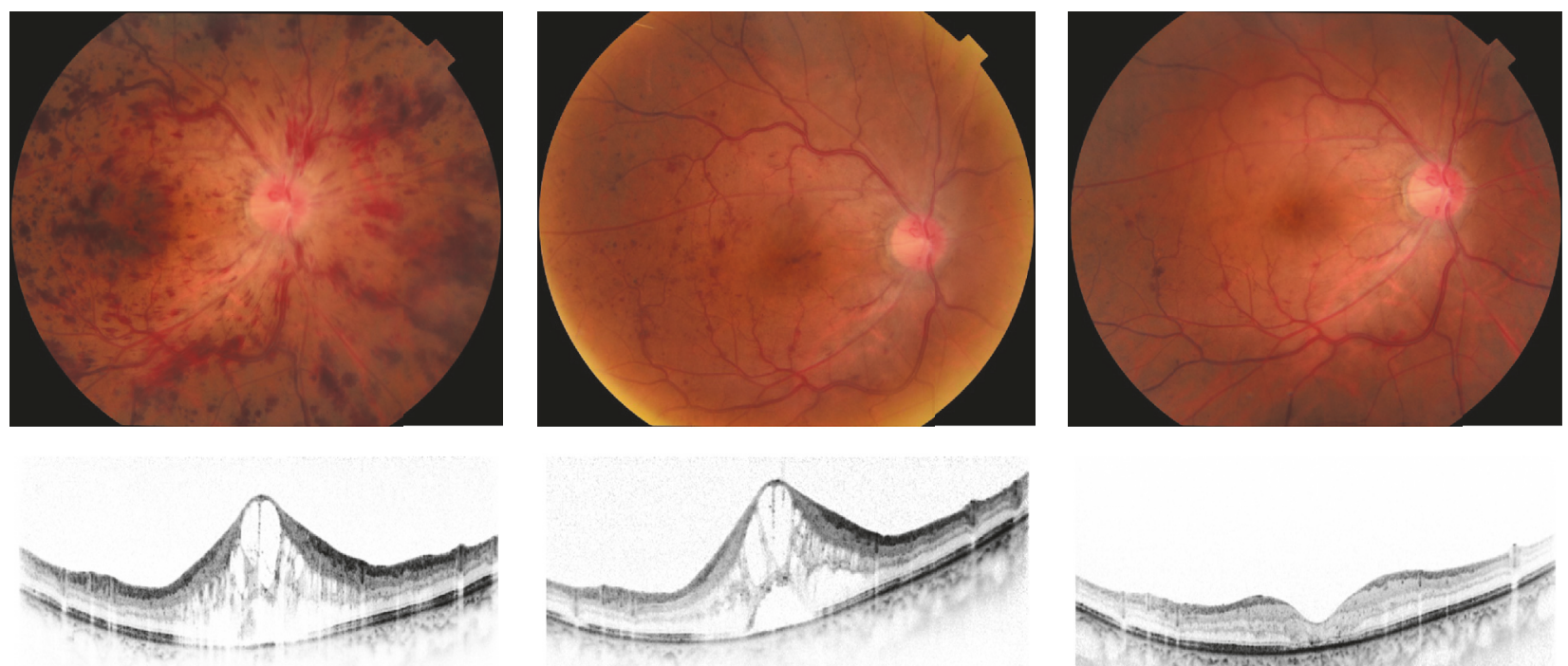

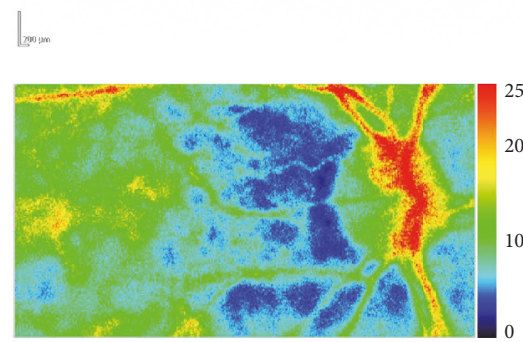

(a)

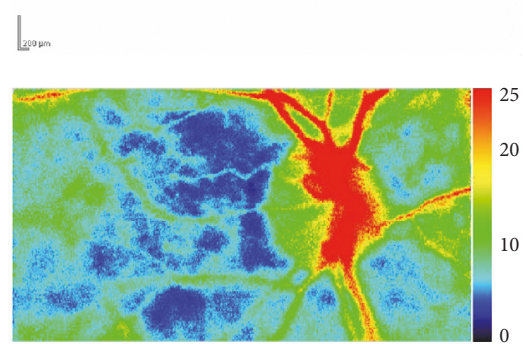

(b)
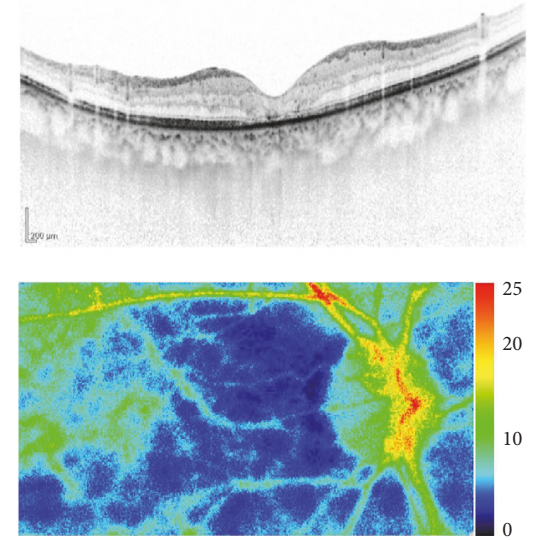

(c)

FIgURE 8: A case of 61-year-old man, CRVO with macular edema (naïve case). His ocular fundus with macular OCTs and imaging of laser speckle flowgraphy at the initial visit (a), after one month of intravitreal injection of aflibercept (b), and after three times of injection (c). Macular edema was not resolved with single injection and his visual acuity was unchanged of 20/100. After three times of anti-VEGF therapy, the macular edema was resolved with visual acuity of 20/60. Chorioretinal blood flow was unchanged one month after anti-VEGF therapy but decreased after three times of anti-VEGF therapy with improved vision of 20/60.

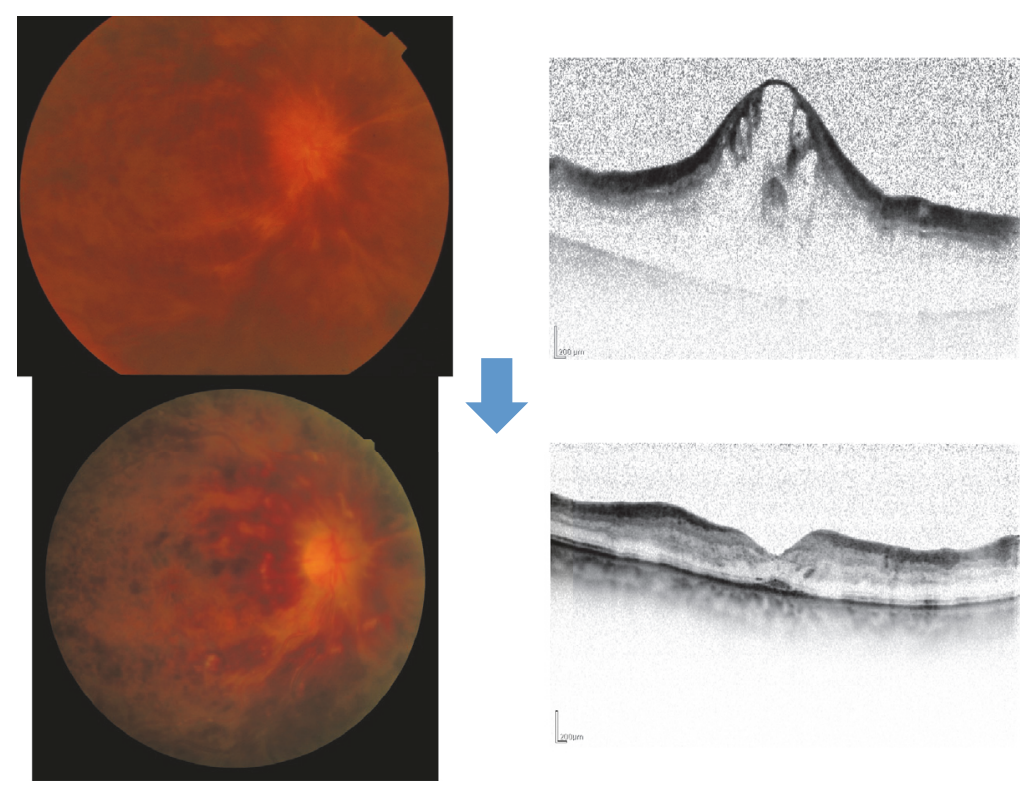

FIGURE 9: A case of 81-year-old female, ischemic CRVO with macular edema. Cotton wool spots were increased one month after intravitreal injection of aflibercept. However, macular edema was dramatically decreased without change of her visual acuity of 20/200. 

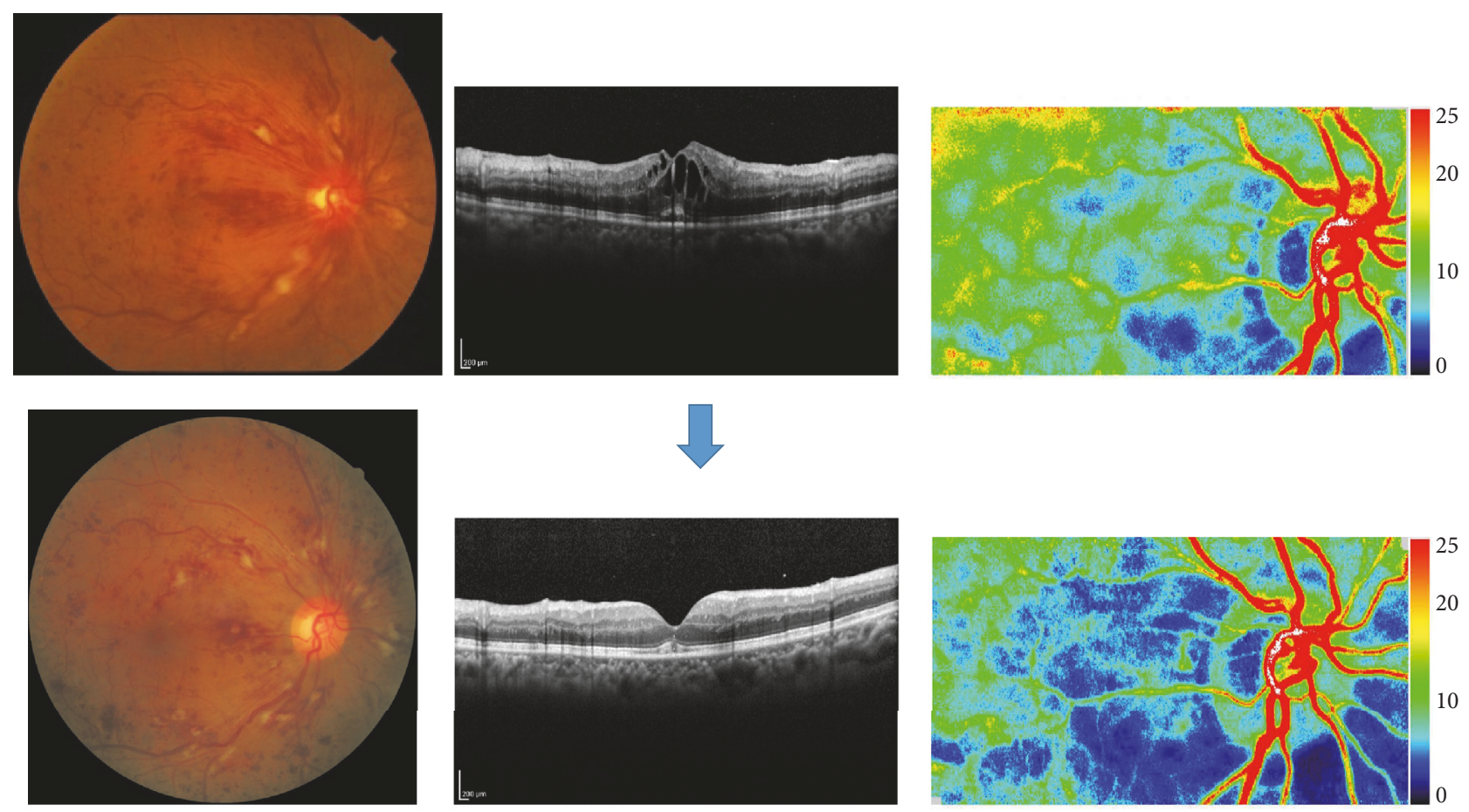

FIGURE 10: A case of 65-year-old man, CRVO with macular edema. Cotton wool spots were increased one month after intravitreal injection of aflibercept. However, macular edema was dramatically decreased, and his visual acuity was improved from 20/60 to 20/20.

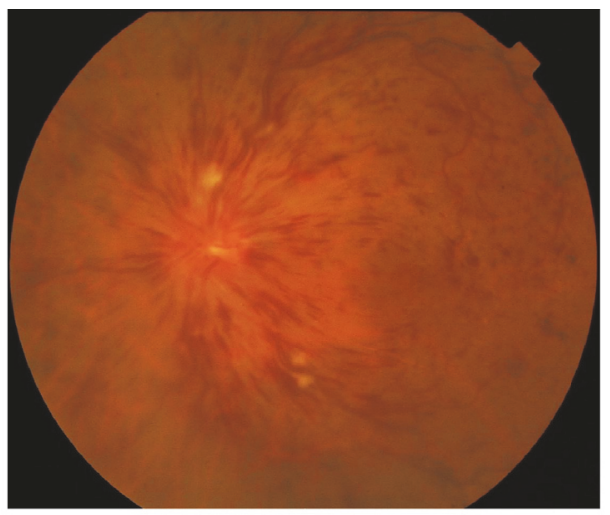

(a)

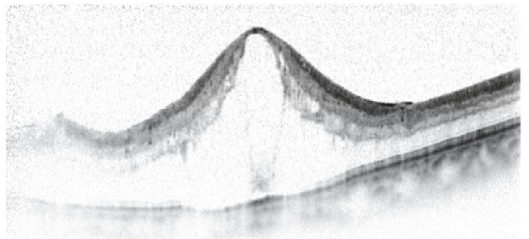

(b)

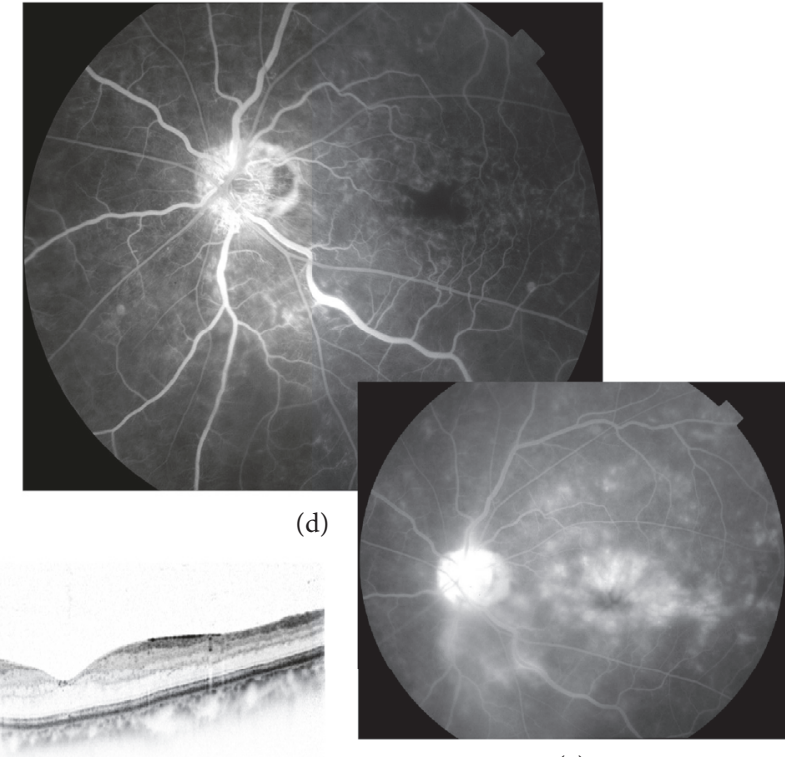

(e)

(c)

FIGURE 11: A case of 87-year-old man, CRVO with macular edema. His macular edema was dramatically decreased after intravitreal injection of aflibercept ((b) and (c)). His visual acuity was improved only a little from 20/200 to 20/100. His FA showed the enlargement of foveal avascular zone (FAZ) in early phase (d). His OCT finding (c) after the treatment looked normal macular shape, but the photo in the late phase of FA showed fluorescein leak in the macula (e). 


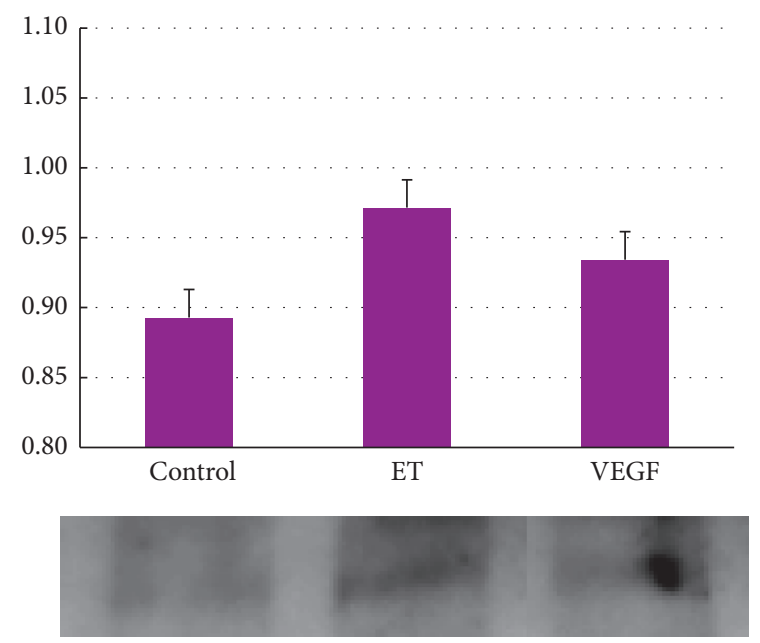

(a)

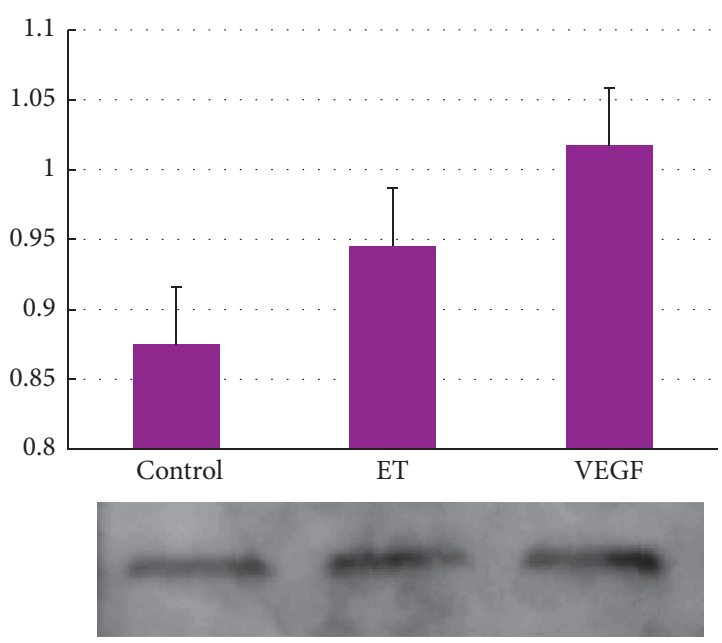

(b)

FIGURE 12: Western blot analyses of HIF-1 and VEGF in rat cultured retinal Müller cells, respectively. The exposure to ET-1 and VEGF increased expressions of HIF-1 (a) and VEGF (b).

This indicates that factors other than VEGF are potentially involved as well.

One possible candidate is endothelin. Endothelin-1 (ET1) is a potent vasoconstrictor [107]. It regulates the bloodretinal barrier, stimulates the growth and migration of cells, and regulates axoplasmic transport. It is essential for the maintenance of cardiovascular homeostasis [108]. While ET-1 is mainly produced by vascular endothelial cells under physiological conditions, it can be produced by any other cell under pathological conditions, such as hypoxia or inflammation $[109,110]$. The increase of VEGF points to a local hypoxia $[111,112]$. Hypoxic cells oxidize less of the hypoxia-inducible factor-1 alpha (HIF). The nonoxidized HIF is a transcription factor that upregulates the transcription of many genes. As a result, VEGF, ET-1, or erythropoietin and other molecules are overexpressed (Figure 12).

With this in mind, we conducted a prospective study to evaluate changes in ET-1 following an injection of intravitreal bevacizumab (IVB), which is the anti-VEGF agent with the longest serum half-life [113], to determine its effect on BRVO-related macular edema [114]. We found that plasma ET-1 levels dropped and macular edema was resolved after anti-VEGF therapy in most patients (Figure 13). However, some patients showed an increase in the plasma ET-1 level with slightly decreased visual acuity. It means that antiVEGF agents reduce intraocular VEGF levels and blood ET-1 levels.

The overexpression of VEGF hints at a simultaneous overexpression of ET-1, and, most probably, both VEGF and ET-1 are involved in the pathogenesis of RVO-related macular edema. VEGF is known to stimulate the production of NO, which is an endothelium-derived relaxing factor, and then increases the blood flow, as described in RVO and Ocular Circulation. If the relation among VEGF, NO, and ET-1 became unbalanced in the retina, RVO might occur. It is known that a reduction of VEGF normally also leads to a reduction in ET-1 $[115,116]$. However, the reactive increase in the ET-1 level after treatment with the anti-VEGF agent raises the question of whether or not the combination of an anti-VEGF therapy with an anti-ET-1 treatment could improve visual prognosis in these patients. In most RVO patients, anti-ET-1 treatment might not be necessary because anti-VEGF agents can neutralize their intraocular VEGF levels.

In an RVO experiment, ET-1 blockers were found to improve retinal circulation $[117,118]$. In patients with RVO, calcium channel blockers for systemic hypertension and reducing vasospasm were found to reduce retinal venous pressure $[119,120]$. This partly reduces the effect of ET1. Finally, Figures 14 and 15 introduce our simple animal experiment of retinal vasospasm by ET-1. Changes of vessels in ocular fundus following intravenous injection of ET-1 in rats were investigated. The vasospasm in one of retinal vessels was observed 30 minutes after the injection of ET-1 (Figure 14). In addition, retinal blood flow by laser speckle flowgraphy before and after intravenous injection of ET1 in rats was measured at the same time. Interestingly, retinal blood flow was slightly increased 5 minutes after the injection and then decreased at 30 minutes and returned to the initial level 1.5 hours after the injection (Figure 15). This finding might induce the pathological condition of RVO.

\section{Conclusions}

Retinal vein occlusion (RVO) is common retinal vascular disease. Anti-VEGF therapy is now the standard treatment and is effective for RVO-related macular edema in most cases. However, RVO have a variety of clinical conditions and its pathomechanism remains unknown. We provided some ways 

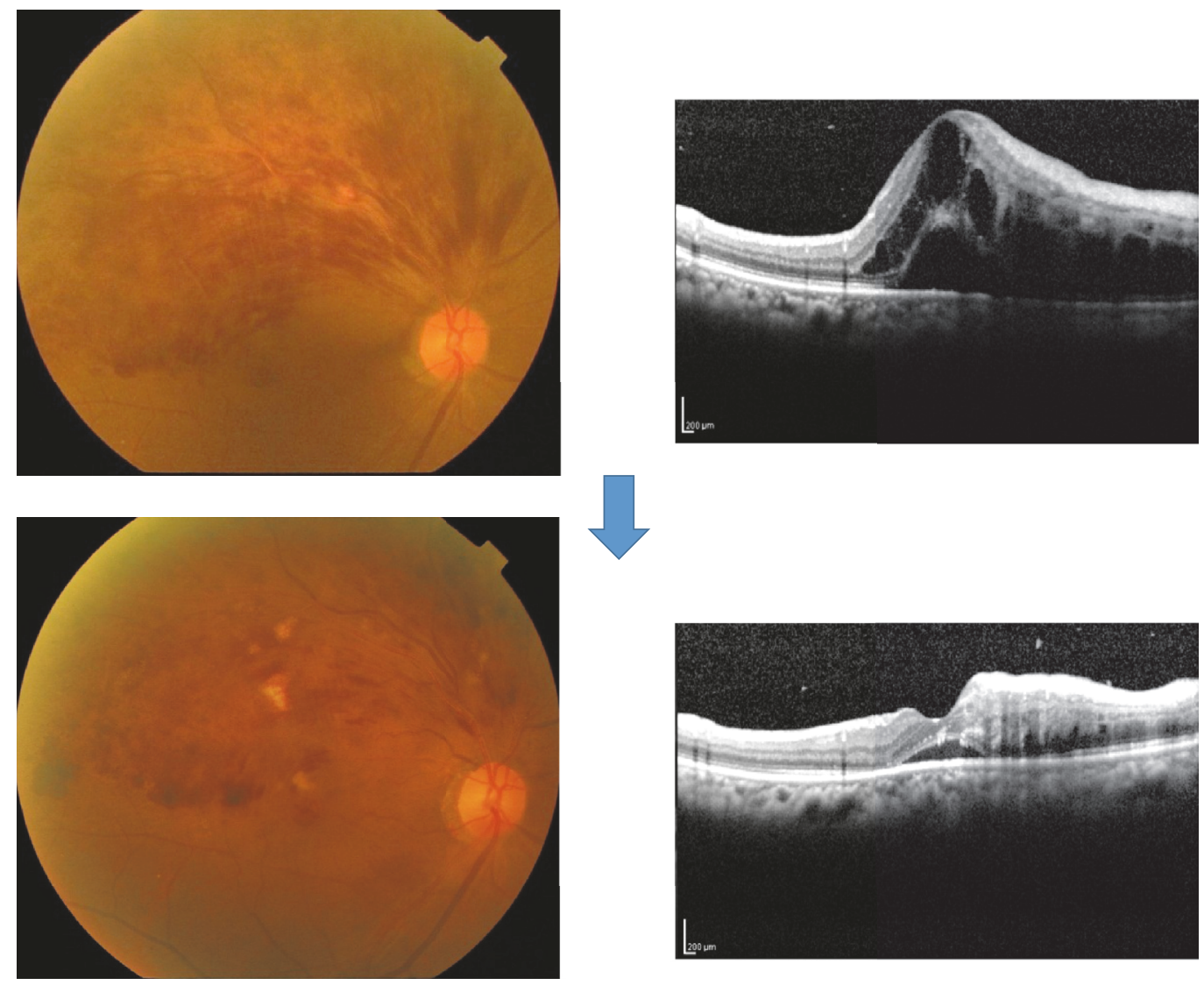

FIGURE 13: A case of 68-year-old female, BRVO with macular edema. Upper: pretreatment; lower: one month after intravitreal injection of bevacizumab (IVB). Macular edema was dramatically decreased and the visual acuity was improved from 2/20 to 8/20 one month after IVB. Plasma ET-1 level was decreased from 1.0567 to $0.568 \mathrm{pg} / \mathrm{mL}$.

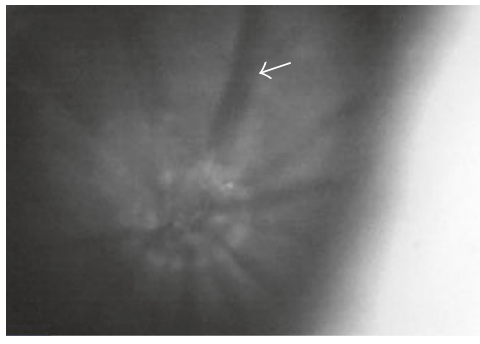

Before

(a)

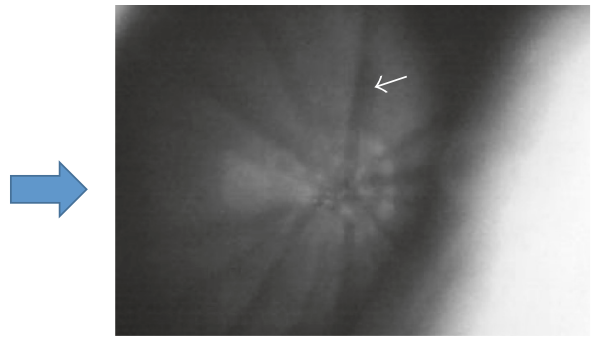

After 30 min.

(b)

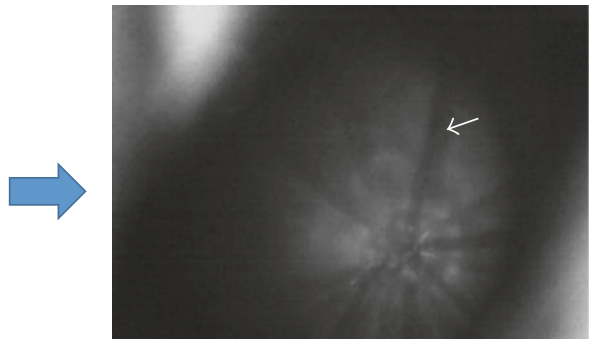

After $1.5 \mathrm{~h}$

(c)

FIGURE 14: Changes of vessels in ocular fundus following intravenous injection of ET-1 in rats. (a) Pretreatment and (b) 30 minutes and (c) 1.5 hours after the injection. The vasospasm (arrow) was observed 30 minutes after the injection.

of distinguishing RVO patients in practice and introduced the vasoactivity of the vein itself and the possible involvement of vasoconstrictors such as ET-1 for the pathogenesis of RVO through our clinical studies, some animal experiments, and recent literatures. Treatment of systemic hypertension and correction of dyslipidemia by improving patients' diets are still important to avoid developing both RVO and cardiovascular diseases [13]. Further investigation is needed to reach the goal of improved 20/20 vision without recurrence in every patient with RVO.

\section{Conflicts of Interest}

The author declares that they have no conflicts of interest. The author has no financial or proprietary interest in any material or method mentioned. 


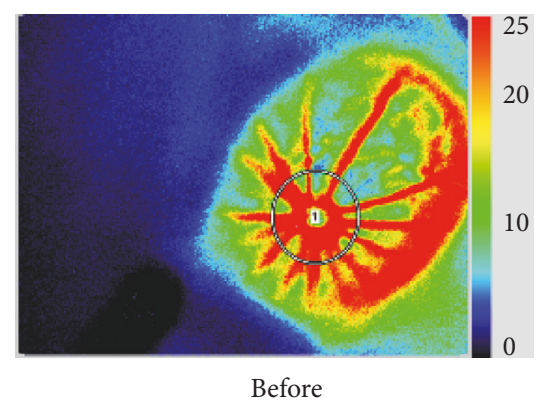

MV: 44.8 MT: 19.0 MV - MT: 25.8

(a)

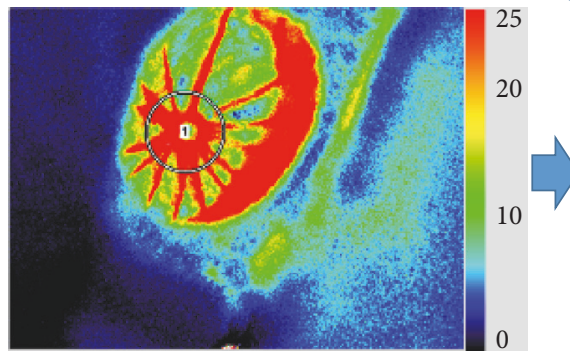

After $30 \mathrm{~min}$.

MV: 39.1 MT: 15.6 MV - MT: 23.5

(c)

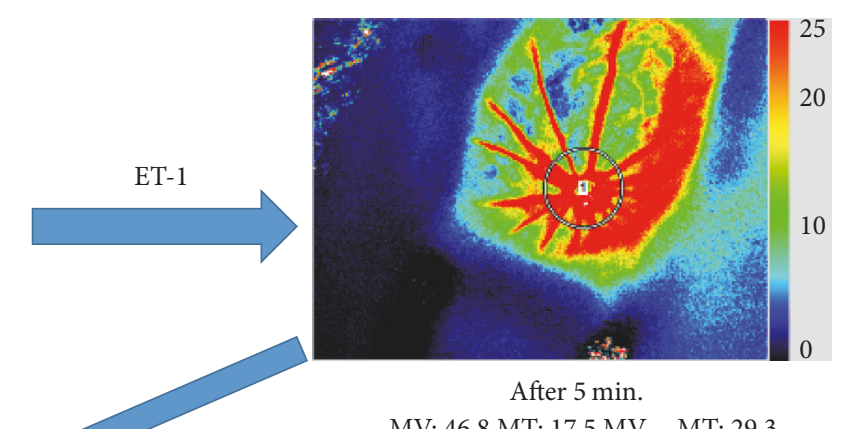

(b)

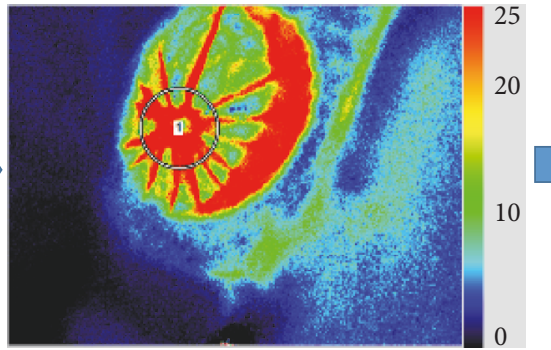

After $1 \mathrm{~h}$

MV: 37.1 MT: 14.4 MV - MT: 22.7

(d)

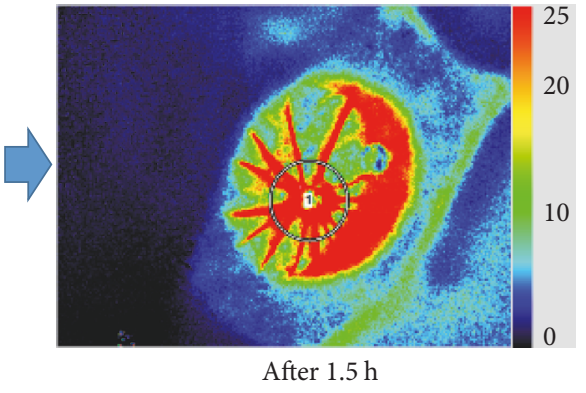

MV: 38.6 MT: 13.4 MV - MT: 25.2

(e)

MV: mean MBR of vascular area

MT: mean MBR of tissue area

FIGURE 15: Measurement of retinal blood flow by laser speckle flowgraphy before and after intravenous injection of ET-1 in rats. (a) Pretreatment, (b) 5 minutes, (c) 30 minutes, (d) 1 hour, and (e) 1.5 hours after the injection. Retinal blood flow (MV-MT) was slightly increased 5 minutes after the injection (b) and then decreased at 30 minutes (c) and returned to the initial level 1.5 hours after the injection (e).

\section{Acknowledgments}

The author deeply thanks Professor Emeritus Josef Flammer, M.D., and Dr. Katarzyna Konieczka, M.D., of University of Basel for discussion. The author also thanks Professor Tsunehiko Ikeda, M.D., Dr. Hidehiro Oku, M.D., Dr. Masanori Fukumoto, M.D., Taeko Horie, of Osaka Medical College, and Dr. Seiyo Harino, M.D., of Harino Eye Clinic for advice on case presentations and for assisting with animal retina experiments. In addition, the author deeply thanks Professor Emeritus Robert Weinreb, M.D., and Dr. John Liu, Ph.D., of Hamilton Glaucoma Center, Department of Ophthalmology, University of California, San Diego (UCSD) for clinical and animal researches of glaucoma when the author was a research fellow at UCSD, 2005-2007.

\section{References}

[1] S. Cugati, J. W. Jie, E. Rochtchina, and P. Mitchell, "Ten-year incidence of retinal vein occlusion in an older population: the blue mountains eye study," Archives of Ophthalmology, vol. 124, no. 5, pp. 726-732, 2006.

[2] R. Klein, S. E. Moss, S. M. Meuer, and B. E. K. Klein, "The 15year cumulative incidence of retinal vein occlusion: the beaver dam eye study," Archives of Ophthalmology, vol. 126, no. 4, pp. 513-518, 2008.

[3] M. Yasuda, Y. Kiyohara, S. Arakawa et al., "Prevalence and systemic risk factors for retinal vein occlusion in a general japanese population: the hisayama study," Investigative Ophthalmology and Visual Science, vol. 51, no. 6, pp. 3205-3209, 2010.

[4] S. L. Rogers, R. L. McIntosh, L. Lim et al., "Natural history of branch retinal vein occlusion: an evidence-based systematic review," Ophthalmology, vol. 117, no. 6, pp. 1094.e5-1101.e5, 2010.

[5] S. S. Hayreh, "Management of central retinal vein occlusion," Ophthalmologica, vol. 217, no. 3, pp. 167-188, 2003.

[6] A. Jaulim, B. Ahmed, T. Khanam, and I. P. Chatziralli, "Branch retinal vein occlusion: epidemiology, pathogenesis, risk factors, clinical features, diagnosis, and complications. An update of the literature," Retina, vol. 33, no. 5, pp. 901-910, 2013.

[7] A. Paton, K. Rubinstein, and V. H. Smith, "Arterial insufficiency in retinal venous occlusion," Transactions of the Ophthalmological Societies of the United Kingdom, vol. 84, pp. 559-595, 1964.

[8] R. S. Clemett, "Retinal branch vein occlusion. changes at the site of obstruction," British Journal of Ophthalmology, vol. 58, no. 5, pp. 548-554, 1974.

[9] L. H. Chuang, N. K. Wang, Y. P. Chen et al., "Vitrectomy and panretinal photocoagulation reduces the occurrence of neovascular glaucoma in central retinal vein occlusion with vitreous hemorrhage," Retina, vol. 33, no. 4, pp. 798-802, 2013.

[10] T. S. Prata, I. Rozenbaum, C. G. V. de Moraes, V. C. Lima, J. Liebmann, and R. Ritch, "Retinal vascular occlusions occur more frequently in the more affected eye in exfoliation syndrome," Eye, vol. 24, no. 4, pp. 658-662, 2010.

[11] C. K. Chan, M. S. Ip, P. C. Vanveldhuisen et al., "SCORE study report \#11: incidences of neovascular events in eyes with retinal 
vein occlusion," Ophthalmology, vol. 118, no. 7, pp. 1364-1372, 2011.

[12] M. Bertelsen, A. Linneberg, N. Christoffersen, H. Vorum, E. Gade, and M. Larsen, "Mortality in patients with central retinal vein occlusion," Ophthalmology, vol. 121, no. 3, pp. 637-642, 2014.

[13] T. Kida, S. Morishita, K. Kakurai, H. Suzuki, H. Oku, and T. Ikeda, "Treatment of systemic hypertension is important for improvement of macular edema associated with retinal vein occlusion," Clinical Ophthalmology, vol. 8, pp. 955-958, 2014.

[14] K. A. Ponto, H. Elbaz, T. Peto et al., "Prevalence and risk factors of retinal vein occlusion: the Gutenberg health study," Journal of Thrombosis and Haemostasis, vol. 13, no. 7, pp. 1254-1263, 2015.

[15] J. Pe'er, R. Folberg, A. Itin, H. Gnessin, I. Hemo, and E. Keshet, "Vascular endothelial growth factor upregulation in human central retinal vein occlusion," Ophthalmology, vol. 105, no. 3, pp. 412-416, 1998.

[16] P. A. Campochiaro, G. Hafiz, S. M. Shah et al., "Ranibizumab for macular edema due to retinal vein occlusions: implication of VEGF as a critical stimulator," Molecular Therapy, vol. 16, no. 4, pp. 791-799, 2008.

[17] A. Pielen, N. Feltgen, C. Isserstedt, J. Callizo, B. Junker, and C. Schmucker, "Efficacy and safety of intravitreal therapy in macular edema due to branch and central retinal vein occlusion: a systematic review," PLoS One, vol. 8, no. 10, Article ID e78538, 2013.

[18] Y. Ogura, J. Roider, J. F. Korobelnik, F. G. Holz, C. Simader, U. Schmidt-Erfurth et al., "Intravitreal aflibercept for macular edema secondary to central retinal vein occlusion: 18-month results of the phase 3 GALILEO study," American Journal of Ophthalmology, vol. 158, no. 5, pp. S0002-9394, 2014.

[19] C. Campa, G. Alivernini, E. Bolletta, M. B. Parodi, and P. Perri, "Anti-VEGF therapy for retinal vein occlusions," Current Drug Targets, vol. 17, no. 3, pp. 328-336, 2016.

[20] H. Noma, H. Funatsu, T. Mimura, S. Harino, and S. Hori, "Vitreous levels of interleukin-6 and vascular endothelial growth factor in macular edema with central retinal vein occlusion," Ophthalmology, vol. 116, no. 1, pp. 87-93, 2009.

[21] H. Noma, T. Mimura, K. Yasuda, and M. Shimura, "Role of soluble vascular endothelial growth factor receptor signaling and other factors or cytokines in central retinal vein occlusion with macular edema," Investigative Ophthalmology and Visual Science, vol. 56, no. 2, pp. 1122-1128, 2015.

[22] M. J. Koss, M. Pfister, F. Rothweiler et al., "Comparison of cytokine levels from undiluted vitreous of untreated patients with retinal vein occlusion," Acta Ophthalmologica, vol. 90, no. 2, pp. e98-e103, 2012.

[23] S. S. Hayreh, M. B. Zimmerman, and P. Podhajsky, "Incidence of various types of retinal vein occlusion and their recurrence and demographic characteristics," American Journal of Ophthalmology, vol. 117, no. 4, pp. 429-441, 1994.

[24] P. Mitchell, W. Smith, and A. Chang, "Prevalence and associations of retinal vein occlusion in Australia: the blue mountains eye study," Archives of Ophthalmology, vol. 114, no. 10, pp. 12431247, 1996.

[25] W. Liu, L. Xu, and J. B. Jonas, "Vein occlusion in Chinese subjects," Ophthalmology, vol. 114, no. 9, pp. 1795-1796, 2007.

[26] N. Cheung, R. Klein, J. J. Wang et al., "Traditional and novel cardiovascular risk factors for retinal vein occlusion: the multiethnic study of atherosclerosis," Investigative Ophthalmology \& Visual Science, vol. 49, no. 10, pp. 4297-4302, 2008.
[27] L. L. Lim, N. Cheung, J. J. Wang et al., "Prevalence and risk factors of retinal vein occlusion in an Asian population," British Journal of Ophthalmology, vol. 92, no. 10, pp. 1316-1319, 2008.

[28] S. S. Hayreh and M. B. Zimmerman, "Branch retinal vein occlusion: natural history of visual outcome," JAMA Ophthalmology, vol. 132, no. 1, pp. 13-22, 2014.

[29] J. Zhao, S. M. Sastry, R. D. Sperduto et al., "Arteriovenous crossing patterns in branch retinal vein occlusion: the eye disease case-control study group," Ophthalmology, vol. 100, no. 3, pp. 423-428, 1993.

[30] Y. Muraoka, A. Tsujikawa, T. Murakami et al., "Morphologic and functional changes in retinal vessels associated with branch retinal vein occlusion," Ophthalmology, vol. 120, no. 1, pp. 91-99, 2013.

[31] S. S. Hayreh, "Prevalent misconceptions about acute retinal vascular occlusive disorders," Progress in Retinal and Eye Research, vol. 24, no. 4, pp. 493-519, 2005.

[32] S. Rogers, R. L. McIntosh, N. Cheung et al., "The prevalence of retinal vein occlusion: pooled data from population studies from the United States, Europe, Asia, and Australia," Ophthalmology, vol. 117, no. 2, pp. 313.el-319.e1, 2010.

[33] P. A. Newman-Casey, M. Stem, N. Talwar, D. C. Musch, C. G. Besirli, and J. D. Stein, "Risk factors associated with developing branch retinal vein occlusion among enrollees in a United States managed care plan," Ophthalmology, vol. 121, no. 10, pp. 19391948, 2014.

[34] P. Kolar, "Risk factors for central and branch retinal vein occlusion: a meta-analysis of published clinical data," Journal of Ophthalmology, vol. 2014, Article ID 724780, 5 pages, 2014.

[35] M. S. Stem, N. Talwar, G. M. Comer, and J. D. Stein, "A longitudinal analysis of risk factors associated with central retinal vein occlusion," Ophthalmology, vol. 120, no. 2, pp. 362-370, 2013.

[36] T. Y. Wong and I. U. Scott, "Clinical practice. retinal-vein occlusion,” New England Journal of Medicine, vol. 363, no. 22, pp. 2135-2144, 2010.

[37] T. Kida, S. Harino, T. Sugiyama, K. Kitanishi, Y. Iwahashi, and T. Ikeda, "Change in retinal arterial blood flow in the contralateral eye of retinal vein occlusion during glucose tolerance test," Graefe's Archive for Clinical and Experimental Ophthalmology, vol. 240, no. 5, pp. 342-347, 2002.

[38] B. E. K. Klein, S. M. Meuer, M. D. Knudtson, and R. Klein, "The relationship of optic disk cupping to retinal vein occlusion: the beaver dam eye study," American Journal of Ophthalmology, vol. 141, no. 5, pp. 859-862, 2006.

[39] H.-F. Chen, M.-C. Chen, C.-C. Lai et al., "Neovascular glaucoma after central retinal vein occlusion in pre-existing glaucoma," BMC Ophthalmology, vol. 14, no. 1, article 119, 2014.

[40] R. David, L. Zangwill, M. Badarna, and Y. Yassur, "Epidemiology of retinal vein occlusion and its association with glaucoma and increased intraocular pressure," Ophthalmologica, vol. 197, no. 2, pp. 69-74, 1988.

[41] Group TCVOS, "Natural history and clinical management of central retinal vein occlusion," Archives of Ophthalmology, vol. 115, no. 4, pp. 486-491, 1997.

[42] S. S. Hayreh, "Classification of central retinal vein occlusion," Ophthalmology, vol. 90, no. 5, pp. 458-474, 1983.

[43] S. E. Bradshaw, S. Gala, M. Nanavaty, A. Shah, M. Mwamburi, and P. Kefalas, "Systematic literature review of treatments for management of complications of ischemic central retinal vein occlusion," BMC Ophthalmology, vol. 16, no. 1, article 104, 2016. 
[44] S. S. Hayreh, L. Fraterrigo, and J. Jonas, "Central retinal vein occlusion associated with cilioretinal artery occlusion," Retina, vol. 28 , no. 4, pp. 581-594, 2008.

[45] A. P. Appiah and C. L. Trempe, "Risk factors associated with branch vs. central retinal vein occlusion," Annals of Ophthalmology, vol. 21, no. 4, pp. 153-155, 1989.

[46] Group TBVOS, "Argon laser scatter photocoagulation for prevention of neovascularization and vitreous hemorrhage in branch vein occlusion: a randomized clinical trial," Archives of Ophthalmology, vol. 104, no. 1, pp. 34-41, 1986.

[47] Group TCVOS, "Baseline and early natural history report. the central vein occlusion study," Archives of Ophthalmology, vol. 111, no. 8, pp. 1087-1095, 1993.

[48] S. S. Hayreh, P. A. Podhajsky, and M. B. Zimmerman, "Natural history of visual outcome in central retinal vein occlusion," Ophthalmology, vol. 118, no. 1, pp. 119-133, 2011.

[49] R. L. McIntosh, S. L. Rogers, L. Lim et al., "Natural history of central retinal vein occlusion: an evidence-based systematic review," Ophthalmology, vol. 117, no. 6, pp. 1113.e15-1123.e15, 2010.

[50] N. J. London, A. Chiang, and J. A. Haller, "The dexamethasone drug delivery system: Indications and evidence," Advances in Therapy, vol. 28, no. 5, pp. 351-366, 2011.

[51] S. Korematsu, H. Goto, C. Gotoh, R. Ohki, T. Kubota, and T. Izumi, "Central retinal vein occlusion in a pediatric patient with SLE and antiphospholipid antibodies without anti-cardiolipin or anti- $\beta 2$ glycoprotein I antibodies," BMC Pediatrics, vol. 14, no. 1, article no. 116, 2014.

[52] M. Silverman, M. J. Lubeck, and W. G. Briney, "Central retinal vein occlusion complicating systemic lupus erythematosus," Arthritis and Rheumatism, vol. 21, no. 7, pp. 839-843, 1978.

[53] C. Ehlken, E. S. Rennel, D. Michels et al., "Levels of VEGF but not VEGF(165b) are increased in the vitreous of patients with retinal vein occlusion," American Journal of Ophthalmology, vol. 152, no. 2, pp. 298-e1, 2011.

[54] J. A. Haller, "Current anti-vascular endothelial growth factor dosing regimens: benefits and burden," Ophthalmology, vol. 120, supplement 5, pp. S3-S7, 2013.

[55] Y. Muraoka, A. Tsujikawa, T. Murakami, K. Ogino, K. Miyamoto, and N. Yoshimura, "Branch retinal vein occlusionassociated subretinal hemorrhage," Japanese Journal of Ophthalmology, vol. 57, no. 3, pp. 275-282, 2013.

[56] Y. Muraoka, A. Tsujikawa, A. Takahashi et al., "Foveal damage due to subfoveal hemorrhage associated with branch retinal vein occlusion," PLOS ONE, vol. 10, no. 12, Article ID e0144894, 2015.

[57] D. McLeod, "Ophthalmoscopic signs of obstructed axoplasmic transport after ocular vascular occlusions," British Journal of Ophthalmology, vol. 60, no. 8, pp. 551-556, 1976.

[58] G. T. Frangieh, W. R. Green, E. Barraquer-Somers, and D. Finkelstein, "Histopathologic study of nine branch retinal vein occlusions," Archives of Ophthalmology, vol. 100, no. 7, pp. 11321140, 1982.

[59] I. O. Haefliger, P. Meyer, J. Flammer, and T. F. Luscher, "The vascular endothelium as a regulator of the ocular circulation: a new concept in ophthalmology?" Survey of Ophthalmology, vol. 39, no. 2, pp. 123-132, 1994.

[60] N. L. B. Christoffersen and M. Larsen, "Pathophysiology and hemodynamics of branch retinal vein occlusion," Ophthalmology, vol. 106, no. 11, pp. 2054-2062, 1999.
[61] I. O. Haefliger, J. Flammer, J.-L. Bény, and T. F. Lüscher, "Endothelium-dependent vasoactive modulation in the ophthalmic circulation," Progress in Retinal and Eye Research, vol. 20, no. 2, pp. 209-225, 2001.

[62] D. J. Browning, "Patchy ischemic retinal whitening in acute central retinal vein occlusion," Ophthalmology, vol. 109, no. 11, pp. 2154-2159, 2002.

[63] A. Catier, M. Paques, and A. Gaudric, "Retinal vasospasm in a case of impending central retinal vein occlusion," Retina, vol. 23, no. 3, pp. 415-417, 2003.

[64] M. Paques and A. Gaudric, "Perivenular macular whitening during acute central retinal vein occlusion," Archives of Ophthalmology, vol. 121, no. 10, pp. 1488-1491, 2003.

[65] D. McLeod, "Why cotton wool spots should not be regarded as retinal nerve fibre layer infarcts," British Journal of Ophthalmology, vol. 89, no. 2, pp. 229-237, 2005.

[66] C. J. Pournaras, E. Rungger-Brandle, C. E. Riva, S. H. Hardarson, and E. Stefansson, "Regulation of retinal blood flow in health and disease," Progress in Retinal and Eye Research, vol. 27, no. 3, pp. 284-330, 2008.

[67] S. Sacu, B. Pemp, G. Weigert et al., "Response of retinal vessels and retrobulbar hemodynamics to intravitreal anti-VEGF treatment in eyes with branch retinal vein occlusion," Investigative Ophthalmology and Visual Science, vol. 52, no. 6, pp. 3046-3050, 2011.

[68] J. Flammer, K. Konieczka, R. M. Bruno, A. Virdis, A. J. Flammer, and S. Taddei, "The eye and the heart," European Heart Journal, vol. 34, no. 17, pp. 1270-1278, 2013.

[69] T. Nagaoka, K. Sogawa, and A. Yoshida, "Changes in retinal blood flow in patients with macular edema secondary to branch retinal vein occlusion before and after intravitreal injection of bevacizumab," Retina, vol. 34, no. 10, pp. 2037-2043, 2014.

[70] M. Matsumoto, K. Suzuma, Y. Fukazawa et al., "Retinal blood flow levels measured by laser speckle flowgraphy in patients who received intravitreal bevacizumab injection for macular edema secondary to central retinal vein occlusion," Retinal Cases and Brief Reports, vol. 8, no. 1, pp. 60-66, 2014.

[71] F. Nitta, H. Kunikata, N. Aizawa et al., "The effect of intravitreal bevacizumab on ocular blood flow in diabetic retinopathy and branch retinal vein occlusion as measured by laser speckle flowgraphy," Clinical Ophthalmology, vol. 8, pp. 1119-1127, 2014.

[72] M. Shahin, M. A. Gad, and W. Hamza, "Impact of intravitreal triamcinolone acetonide versus intravitreal bevacizumab on retrobulbar hemodynamic in patients with diabetic macular edema," Cutaneous and Ocular Toxicology, vol. 33, no. 1, pp. 4953, 2014.

[73] L. S. Lim, L. Tan, and S. Perera, "Retinal vessel oxygen saturation increases after vitrectomy," Investigative Ophthalmology and Visual Science, vol. 55, no. 6, pp. 3851-3856, 2014.

[74] N. Ornek, M. Inal, I. E. Erbahceci, T. Ogurel, and K. Ornek, "Effect of intravitreal bevacizumab on retrobulbar blood flow of patients with diabetic macular edema," European Journal of Ophthalmology, vol. 25, no. 6, pp. 539-545, 2015.

[75] D. Nagasato, Y. Mitamura, K. Semba et al., "Correlation between optic nerve head circulation and visual function before and after anti-VEGF therapy for central retinal vein occlusion: prospective, interventional case series," BMC Ophthalmology, vol. 16, no. 1, article no. 36, 2016.

[76] H. Noma, K. Yasuda, T. Minezaki, S. Watarai, and M. Shimura, "Changes of retinal flow volume after intravitreal injection of bevacizumab in branch retinal vein occlusion with macular 
edema: a case series," BMC Ophthalmology, vol. 16, no. 1, article no. $61,2016$.

[77] M. Matsumoto, K. Suzuma, Y. Yamada, E. Tsuiki, A. Fujikawa, and T. Kitaoka, "Retinal blood flow after intravitreal bevacizumab is a predictive factor for outcomes of macular edema associated with central retinal vein occlusion," Retina, 2017.

[78] M. Okamoto, M. Yamashita, T. Sakamoto, and N. Ogata, "Choroidal blood flow and thickness as predictors for response to anti-vascular endothelial growth factor therapy in macular edema secondary to branch retinal vein occlusion," Retina, 2017.

[79] R. F. Furchgott and J. V. Zawadzki, "The obligatory role of endothelial cells in the relaxation of arterial smooth muscle by acetylcholine," Nature, vol. 288, no. 5789, pp. 373-376, 1980.

[80] J. D. Hood, C. J. Meininger, M. Ziche, and H. J. Granger, "VEGF upregulates ecNOS message, protein, and NO production in human endothelial cells," American Journal of Physiology-Heart and Circulatory Physiology, vol. 274, no. 3, part 2, pp. H1054-H1058, 1998.

[81] T. Kida, T. Sugiyama, H. Oku, S. Harino, and T. Ikeda, "Plasma endothelin-1 levels depress optic nerve head circulation detected during the glucose tolerance test," Graefe's Archive for Clinical and Experimental Ophthalmology, vol. 245, no. 9, pp. 1289-1293, 2007.

[82] T. Kida, A. Tsujikawa, Y. Muraoka et al., "Cotton wool spots after anti-vascular endothelial growth factor therapy for macular edema associated with central retinal vein occlusion," Ophthalmologica, vol. 235, no. 2, pp. 106-113, 2016.

[83] H. Inomata, H. Ikui, and K. Kimura, "Fine structure of cytoid bodies," Japanese Journal of Ophthalmology, vol. 11, pp. 1-14, 1967.

[84] K. S. Kim, H. R. Chang, and S. Song, "Ischaemic change after intravitreal bevacizumab (Avastin) injection for macular oedema secondary to non-ischaemic central retinal vein occlusion," Acta Ophthalmologica, vol. 86, no. 8, pp. 925-927, 2008.

[85] D. N. Papadopoulou, E. Mendrinos, G. Mangioris, G. Donati, and C. J. Pournaras, "Intravitreal ranibizumab may induce retinal arteriolar vasoconstriction in patients with neovascular age-related macular degeneration," Ophthalmology, vol. 116, no. 9, pp. 1755-1761, 2009.

[86] M. Shimura and K. Yasuda, "Macular ischaemia after intravitreal bevacizumab injection in patients with central retinal vein occlusion and a history of diabetes and vascular disease," British Journal of Ophthalmology, vol. 94, no. 3, pp. 381-383, 2010.

[87] A. M. Mansour, L. A. Bynoe, J. C. Welch et al., "Retinal vascular events after intravitreal bevacizumab," Acta Ophthalmologica, vol. 88, no. 7, pp. 730-735, 2010.

[88] N. R. Kim and H. S. Chin, "Progression of impending central retinal vein occlusion to the ischemic variant following intravitreal bevacizumab," Korean journal of ophthalmology: KJO, vol. 24, no. 3, pp. 179-181, 2010.

[89] T. Von Hanno, B. Kinge, and K. Fossen, "Retinal artery occlusion following intravitreal anti-VEGF therapy," Acta Ophthalmologica, vol. 88, no. 2, pp. 263-266, 2010.

[90] K. Manousaridis and J. Talks, "Macular ischaemia: a contraindication for anti-VEGF treatment in retinal vascular disease?" British Journal of Ophthalmology, vol. 96, no. 2, pp. 179-184, 2012.

[91] T. Meyer, L. Robles-Carrillo, T. Robson et al., "Bevacizumab immune complexes activate platelets and induce thrombosis in FCGR2A transgenic mice," Journal of Thrombosis and Haemostasis, vol. 7, no. 1, pp. 171-181, 2009.
[92] R. K. Andrews, E. E. Gardiner, Y. Shen, and M. C. Berndt, "Platelet interactions in thrombosis," IUBMB Life, vol. 56, no. 1, pp. 13-18, 2004.

[93] N. Suzuki, Y. Hirano, M. Yoshida et al., "Microvascular abnormalities on optical coherence tomography angiography in macular edema associated with branch retinal vein occlusion," American Journal of Ophthalmology, vol. 161, pp. 126-132el, 2016.

[94] R. Mastropasqua, L. Di Antonio, S. Di Staso et al., "Optical coherence tomography angiography in retinal vascular diseases and choroidal neovascularization," Journal of Ophthalmology, vol. 2015, Article ID 343515, 8 pages, 2015.

[95] F. Coscas, A. Glacet-Bernard, A. Miere et al., "Optical coherence tomography angiography in retinal vein occlusion: evaluation of superficial and deep capillary plexa," American Journal of Ophthalmology, vol. 161, pp. 160-171e2, 2016.

[96] K. Kumagai, A. Tsujikawa, Y. Muraoka et al., "Three-dimensional optical coherence tomography evaluation of vascular changes at arteriovenous crossings," Investigative Ophthalmology and Visual Science, vol. 55, no. 3, pp. 1867-1875, 2014.

[97] Y. Muraoka, A. Tsujikawa, K. Kumagai et al., "Retinal vessel tortuosity associated with central retinal vein occlusion: An optical coherence tomography study," Investigative Ophthalmology and Visual Science, vol. 55, no. 1, pp. 134-141, 2013.

[98] M. Paques, A. Brolly, J. Benesty et al., "Venous nicking without arteriovenous contact: the role of the arteriolar microenvironment in arteriovenous nickings," JAMA Ophthalmology, vol.133, no. 8, pp. 947-950, 2015.

[99] D. Yu, E. Su, S. J. Cringle, W. H. Morgan, I. L. McAllister, and P. K. Yu, "Local modulation of retinal vein tone," Investigative Opthalmology \& Visual Science, vol. 57, no. 2, p. 412, 2016.

[100] M. H. Kang, C. Balaratnasingam, P. K. Yu et al., "Morphometric characteristics of central retinal artery and vein endothelium in the normal human optic nerve head," Investigative Ophthalmology and Visual Science, vol. 52, no. 3, pp. 1359-1367, 2011.

[101] T. Kida, M. Fukumoto, T. Sato, H. Oku, and T. Ikeda, "Clinical features of Japanese patients with central retinal vein occlusion complicated by normal-tension glaucoma: a retrospective study," Ophthalmologica, vol. 237, no. 3, pp. 173-179, 2017.

[102] W. H. Morgan, M. L. Hazelton, and D.-Y. Yu, "Retinal venous pulsation: Expanding our understanding and use of this enigmatic phenomenon," Progress in Retinal and Eye Research, vol. 55, pp. 82-107, 2016.

[103] J. H. Seo, T.-W. Kim, R. N. Weinreb, Y. A. Kim, and M. Kim, "Relationship of intraocular pressure and frequency of spontaneous retinal venous pulsation in primary open-angle glaucoma," Ophthalmology, vol. 119, no. 11, pp. 2254-2260, 2012.

[104] S. A. Vinores, A. I. Youssri, J. D. Luna et al., "Upregulation of vascular endothelial growth factor in ischemic and nonischemic human and experimental retinal disease," Histology and Histopathology, vol. 12, no. 1, pp. 99-109, 1997.

[105] P. A. Campochiaro, "Molecular pathogenesis of retinal and choroidal vascular diseases," Progress in Retinal and Eye Research, vol. 49, pp. 67-81, 2015.

[106] P. A. Campochiaro, "Anti-vascular endothelial growth factor treatment for retinal vein occlusions," Ophthalmologica, vol. 227, no. 1, pp. 30-35, 2012.

[107] M. Yanagisawa, "A novel potent vasoconstrictor peptide produced by vascular endothelial cells," Nature, vol. 332, pp. 411$415,1988$.

[108] A. Loesch, "Perivascular nerves and vascular endothelium: recent advances," Histol Histopathol, vol. 17, pp. 591-597, 2002. 
[109] Y. Koyama, M. Hayashi, R. Nagae, S. Tokuyama, and T. Konishi, "Endothelin-1 increases the expression of VEGF-R1/Flt-1 receptors in rat cultured astrocytes through ETB receptors," Journal of neurochemistry, vol. 130, no. 6, pp. 759-769, 2014.

[110] D. W. Anggrahini, N. Emoto, K. Nakayama et al., "Vascular endothelial cell-derived endothelin-1 mediates vascular inflammation and neointima formation following blood flow cessation," Cardiovascular Research, vol. 82, no. 1, pp. 143-151, 2009.

[111] D. V. Faller, "Endothelial cell responses to hypoxic stress," Clinical and Experimental Pharmacology and Physiology, vol. 26, no. 1, pp. 74-84, 1999.

[112] J. Stone, A. Itin, T. Alon et al., "Development of retinal vasculature is mediated by hypoxia-induced vascular endothelial growth factor (VEGF) expression by neuroglia," Journal of Neuroscience, vol. 15, no. (7 Pt 1), pp. 4738-4747, 1995.

[113] M. W. Stewart, "Pharmacokinetics, pharmacodynamics and pre-clinical characteristics of ophthalmic drugs that bind VEGF," Expert Review of Clinical Pharmacology, vol. 7, no. 2, pp. 167-180, 2014.

[114] T. Kida, J. Flammer, H. Oku et al., "Suppressed endothelin-1 by anti-VEGF therapy is important for patients with BRVO-related macular edema to improve their vision," EPMA Journal, vol. 7, no. 1, article 18, 2016.

[115] A. Matsuura, W. Yamochi, K.-I. Hirata, S. Kawashima, and M. Yokoyama, "Stimulatory interaction between vascular endothelial growth factor and endothelin-1 on each gene expression," Hypertension, vol. 32, no. 1, pp. 89-95, 1998.

[116] G. P. Star, M. Giovinazzo, E. Lamoureux, and D. Langleben, "Effects of vascular endothelial growth factor on endothelin-1 production by human lung microvascular endothelial cells in vitro," Life sciences, vol. 118, no. 2, pp. 191-194, 2014.

[117] A. N. Stangos, I. K. Petropoulos, J. A. Pournaras, Mendrinos E, and Pournaras C. J., "The vasodilatory effect of juxta-arteriolar microinjection of endothelinA receptor inhibitor in healthy and acute branch retinal vein occlusion minipig retinas," Invest Ophthalmol Vis Sci, vol. 51, no. 4, pp. 2185-2190, 2010.

[118] S. Salvatore and E. M. Vingolo, "Endothelin-1 role in human eye: a review," Journal of Ophthalmology, vol. 2010, pp. 1-10, 2010.

[119] H. Hara, N. Toriu, and M. Shimazawa, "Clinical potential of lomerizine, a Ca2+ channel blocker as an anti-glaucoma drug: effects on ocular circulation and retinal neuronal damage," Cardiovascular Drug Reviews, vol. 22, no. 3, pp. 199-214, 2004.

[120] L. Fang, S. Turtschi, and M. Mozaffarieh, "The effect of nifedipine on retinal venous pressure of glaucoma patients with the Flammer-Syndrome," Graefe's Archive for Clinical and Experimental Ophthalmology, vol. 253, no. 6, pp. 935-939, 2015. 


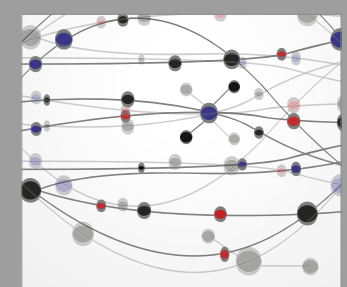

The Scientific World Journal
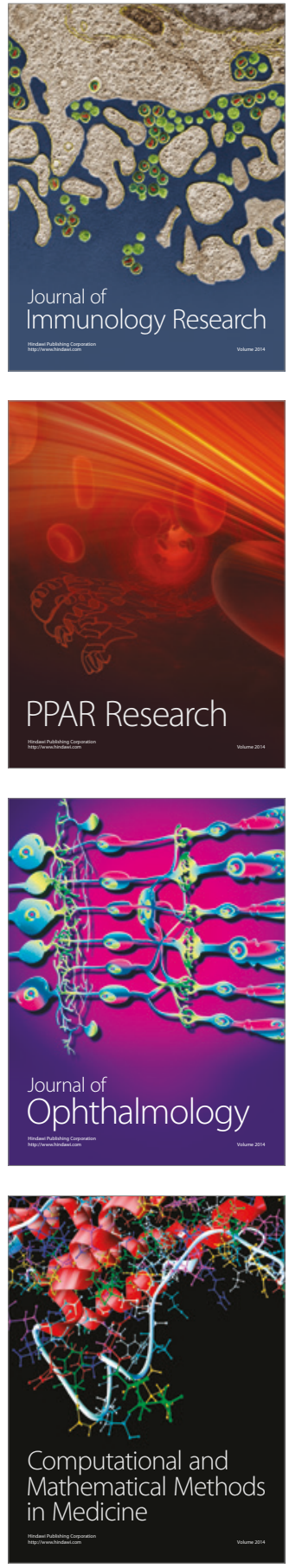

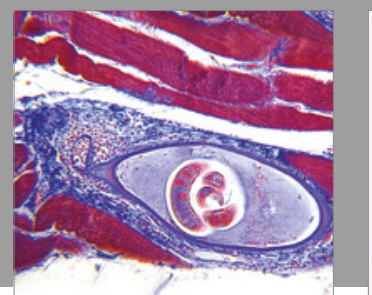

Gastroenterology Research and Practice
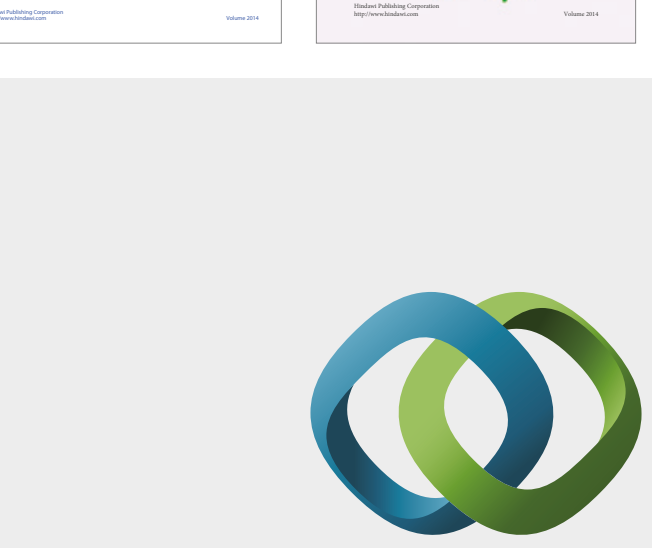

\section{Hindawi}

Submit your manuscripts at

https://www.hindawi.com
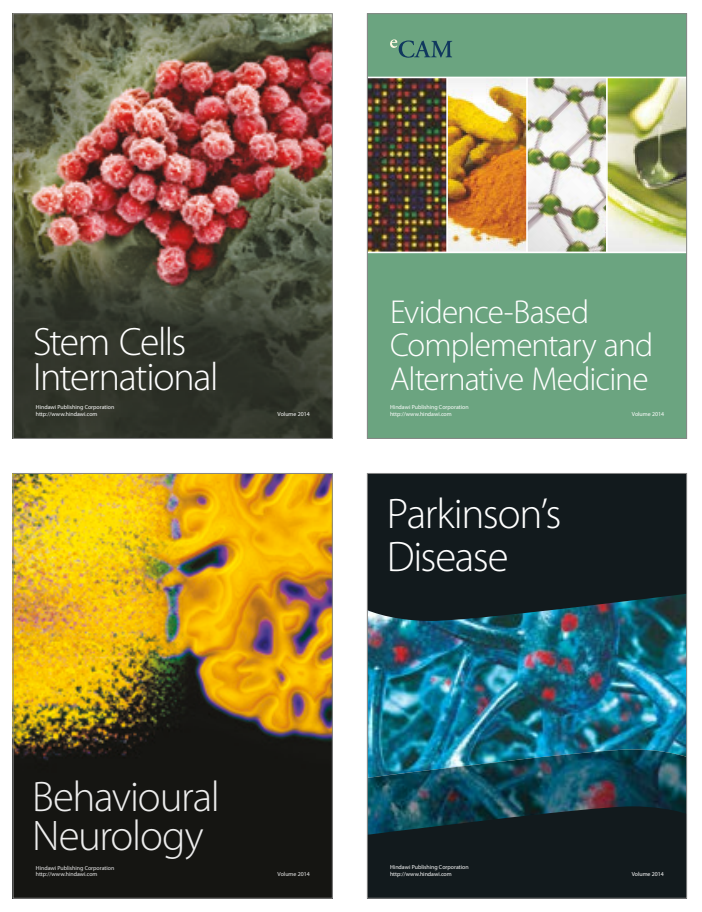
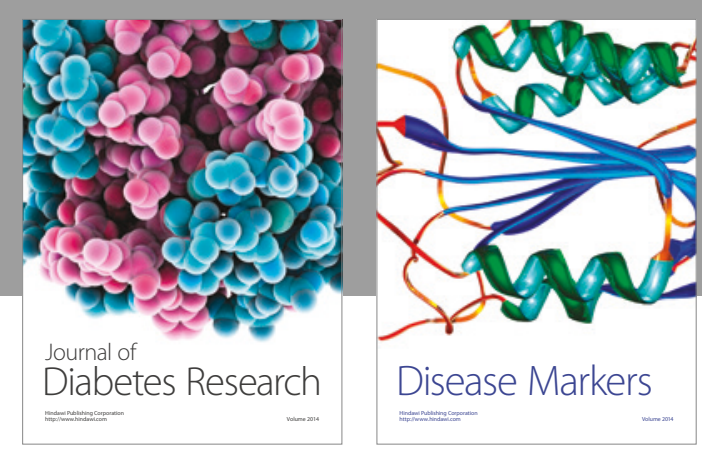

Disease Markers
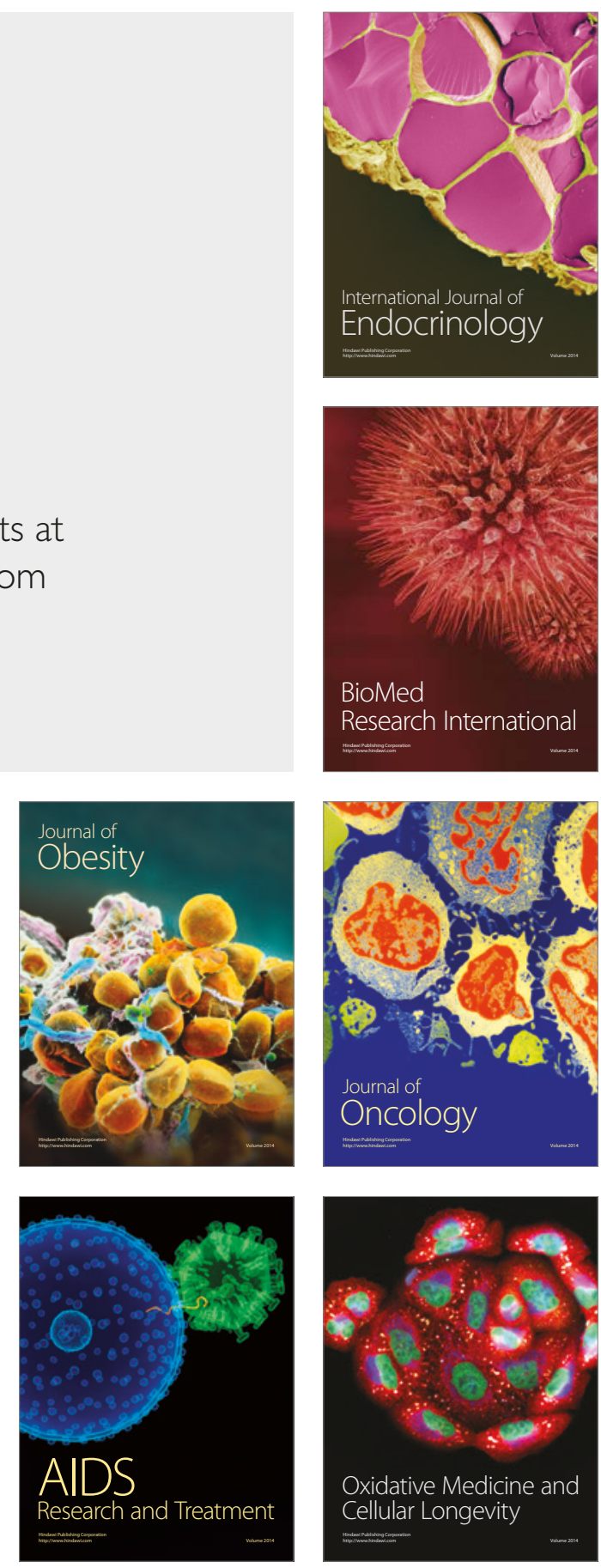